\title{
6 Die Radikalisierung sozialer Konflikte im Kontext von Masseneinwanderung und Rassismen, 1870-1900
}

Bestimmend für die Arbeitsverfassung der USA während des Gilded Age wurden neben den Klassenkämpfen und Streiks die rechtlichen und ökonomischen Diskriminierungen, die das System des Rassismus erzeugte, indem Weiß gegen Schwarz, Eingewanderte gegen Alteingesessene und Englisch sprechende Menschen gegen die polyglotte Masse des „Rests“ ausgrenzend gegenüber gestellt wurden. White Ango-Saxon Protestants (WASP) reagierten gegen die Einwanderung von ethnischen Gruppen, die nicht „weiß“ waren oder nicht einer der traditionellen protestantischen Glaubensrichtungen anhingen. Die Zuwanderung von billigen Arbeitskräften aus China und die Gegenwart spanisch-sprechender „Californios“ gaben den rassistischen Gruppen im Lande Auftrieb. Die Reaktion gegen Immigrantinnen und Immigranten und die rassistische Abwehr gegen $A f$ rican Americans müssen als Teil des gleichen Dispositivs gesehen werden, unter dem auch den Native Americans das Lebensrecht abgesprochen wurde, auch dann, wenn sich die Rassismen gegen Zugewanderte und African Americans in seinen Formen durchaus wandelbar zeigten. Dieser Lock-in des rassistischen Dispositivs baute historisch auf dem System der rassistischen Suprematie des Südens auf, extendierte und modifizierte in Übereinstimmung mit dem Sozialdarwinismus im Zusammenhang mit der Vertreibung der Native Americans und perpetuierte und exportierte es unter den Bedingungen der Industrialisierung in den Norden, wo es hervorragend instrumentalisiert werden konnte, um Arbeitskämpfe auszubremsen oder aufzuweichen. Damit entsprechen die vorangegangenen Lock-ins 1-4 der Critical Juncture (Critical Juncture 7), die für das Lock-in des Rassismus bestimmend waren (Lock-in 7) Den Massen der diskriminierten Einwanderer aus Süd- und Osteuropa gegenüber standen African Americans, die mithilfe von Auswanderungsgesetzen aus dem Land geschafft werden sollten. ${ }^{1}$

1 Upchurch, Legislating Racism, S. 23-45. Breitzer, Susan Roth. Race, Immigration, and Contested Americanness: Black Nativism and the American Labor Movement, 1880-1930. Race/ Ethnicity: Multidisciplinary Global Contexts. 2011; 4 (2):269-283. Omatsu, Glenn. Racism or Solidarity? Unions and Asian Immigrant Workers. The Radical Teacher. 1995; (46) :33-37. Zur Politik der gewerkschaftlichen Rassentrennung und zum AFL im Süden Honey, Michael K. Southern Labor and Black Civil Rights: Organizing Memphis Workers. Urbana, IL: University of Illinois Press, 1993. Ausnahmen bestätigten die Regel. Gerteis, Joseph. Class and the Color Line: Interracial Class Coalition in the Knights of Labor and the Populist Movement. Durham, NC: Duke University Press, 2007.

Ә OpenAccess. () 2019 M. Michaela Hampf, publiziert von De Gruyter. (cc) BY-NC-ND Dieses Werk ist lizenziert unter der Creative Commons Attribution-NonCommercial-NoDerivatives 4.0. https://doi.org/10.1515/9783110657746-008 
Aus rassistischen Gründen diskriminierte afroamerikanische Arbeiter und Arbeiterinnen konnten als Streikbrecher eingesetzt werden. ${ }^{2}$ Die rassistischen Überzeugungen eines großen Teils der Facharbeitergewerkschaften stützten dabei dieses System nachhaltig. In den Diskussionen um den Eintritt der USA in ein koloniales System des Empire diente dieser internalisierte Rassismus als Rechtfertigung der imperialen Ansprüche der USA gegenüber people of color.

\subsection{Klassenkämpfe, Streiks und die Etablierung eines Systems der rechtlichen und ökonomischen Diskriminierung, 1877-1882}

Im Zusammenhang mit der Diskussion der Westexpansion und der Urbanisierung wurde hier ja schon auf das Paradox hingewiesen, dass die Migration in den USA in der Zeit der Industrialisierung in zwei entgegengesetzte Richtungen verlief. Zum einen zogen immer mehr amerikanische Familien in den Westen und versuchten ihr Glück als Farmer auf einem Stück Land, auf dem 20 Jahre zuvor noch Native Americans gelebt hatten, zum anderen strömte die Landbevölkerung nach dem Bürgerkrieg in die Städte und wurde Teil der Industriearbeiterschaft. Industriestädte wie Pittsburgh, Chicago, New York und Detroit zogen Familien und Einzelpersonen vom Land magnetisch an. Hinzu kamen die Millionen von Migranten und Migrantinnen, die aus politischen, wirtschaftlichen oder kulturellen Gründen ihre Heimat in Europa und Asien verließen und in die USA einwanderten. Die Wanderungsbewegung von den landwirtschaftlichen Peripherien in die industriellen Zentren war somit Teil einer globalen Wanderung. Menschen aus Irland, China, Italien, Russland und Österreich-Ungarn verließen ihre Heimat ja nicht nur, um nach Nordamerika auszuwandern. Argentinien nahm im 19. Jahrhundert große Mengen von Migranten italienischer Abstammung auf. Deutsche gingen nach Brasilien. ${ }^{3}$ Der Arbeiterhistoriker David Montgomery fasste diese

2 Fusfeld, Daniel Roland and Bates, Timothy Mason. The Political Economy of the Urban Ghetto. Carbondale, IL: Southern Illinois University Press, 1984, S.19f. Bracey, John H., Meier, August und Rudwick, Elliott M. (Hg.). Black Workers and Organized Labor. Belmont, CA: Wadsworth Pub. Co, 1971. Moreno, Paul D. Black Americans and Organized Labor: A New History. Baton Rouge, LA: Louisiana State University Press, 2006. Salmond, John A. Southern Struggles: The Southern Labor Movement and the Civil Rights Struggle. Gainesville, FL: University Press of Florida, 2004. Zieger, Robert H. For Jobs and Freedom: Race and Labor in America Since 1865. Lexington, KY: University Press of Kentucky, 2007.

3 Baily, Samuel L. Immigrants in the Lands of Promise: Italians in Buenos Aires and New York City, 1870 - 1914. Ithaca, NY: Cornell University Press, 1999. Baily, Samuel L. und Míguez, Eduardo 
globale Wanderung treffend zusammen, als er schrieb „,...] the rural periphery of the nineteenth century industrial world became the primary source of supply for ,human machines“." “4 Gerade die Trennung der Arbeiterschaft in unterschiedliche Ethnien, Religionen und Sprachgruppen erschwerte die Herstellung übergreifender Solidarität (Critical Juncture). Dem entgegen wirkte die alltägliche Erfahrung gemeinsamer Ausbeutung. Weit verbreitete Kinderarbeit in Gruben und Fabriken, die Notwendigkeit, nicht zur Familie gehörende Hausgäste aufzunehmen, um die Miete bezahlen zu können, und das Erfordernis der Mitarbeit von Frauen, weil der Lohn des Mannes als „Haupternährer“ nicht ausreichte, waren Erfahrungen, die jede Familie unabhängig von Herkunftsland, Bekenntnis oder Hautfarbe machte.

Tabelle 9: Durchschnittliche Jahreslöhne der Industriearbeiter 1849-1909

\begin{tabular}{lrrr}
\hline Jahr & Produktionsarbeiter & Lohnsummen & Jahreslohn in \$ \\
\hline 1849 & 957.000 & 237.000 .000 & 247 \\
1859 & 1.311 .000 & 379.000 .000 & 289 \\
1869 & 2.054 .000 & 621.000 .000 & 302 \\
1879 & 2.733 .000 & 948.000 .000 & 346 \\
1889 & 4.129 .000 & 1.821 .000 .000 & 441 \\
1899 & 4.502 .000 & 1.893 .000 .000 & 420 \\
1904 & 5.182 .000 & 2.441 .000 .000 & 471 \\
1909 & 6.262 .000 & 3.205 .000 .000 & 511 \\
\hline
\end{tabular}

Unterschiedliche ethnische Herkunft und unterschiedliche Qualifizierung korrelierten. Die Carnegie-Stahlfabrik vor den Toren Pittsburghs ist ein gutes Beispiel für die globale Vernetzung des Arbeitsmarktes. Als Andrew Carnegie seine erste Stahlfabrik im Jahre 1872 eröffnete, stellte sein Generaldirektor William R. Jones

José. Mass Migration to Modern Latin America. Wilmington, DE: Scholarly Resources, 2003. Braun, Felipe Kuhn. História Da Imigraçao Alema No Sul Do Brasil. Porte Alegre: Costoli Soluções Gráficas, 2010. Dreher, Martin Norberto, Jung, Greisi Fabiane Griesang, Mugge, Miquéias Henrique und Seifert, Keity Link. Degredados De Mecklenburg-Schwerin e Os Primórdios Da Imigraçao Alema No Brasil. São Leopoldo: Oikos Editora, 2010. Grützmann, Imgart, Dreher, Martin Norberto und Feldens, Jorge Augusto. Imigração Alemã No Rio Grande Do Sul Recortes. São Leopoldo, RS: Okos Editora. UNISINOS, 2008. Neumann, Gerson Roberto. Brasilien ist nicht weit von hier! Die Thematik der deutschen Auswanderung nach Brasilien in der deutschen Literatur im 19. Jahrhundert (1800 - 1871). Frankfurt am Main, New York: P. Lang, 2005.

4 Montgomery, David. The Fall of the House of Labor: The Workplace, the State, and American Labor Activism, 1865-1925. Cambridge, New York, Paris: Cambridge University Press. Editions de la Maison des Sciences de l'Homme, 1987, S. 68. 
(1839-1889) mit Vorliebe Arbeiter aus der ländlichen Umgebung Pennsylvanias ein. Zwanzig Jahre später bestand die Belegschaft Carnegies aus Bauernjungs mit einem gänzlich anderen geographischen Hintergrund. Nun überwogen Zuwanderer aus Österreich-Ungarn, die gerade in die USA gekommen und bereit waren, für niedrige Löhne zu arbeiten. Trotz des riesigen Bedarfs an Industriearbeitern nach dem Bürgerkrieg blieben die Löhne niedrig, denn die Unternehmer konnten diesen Bedarf weitgehend mit Neuankömmlingen aus Europa und Asien decken. Während der Wirtschaftskrisen von 1873 bis 1878 und von 1893 bis 1898 fielen die Nominallöhne sogar dramatisch und erholten sich nur langsam bis zum Jahr 1900. ${ }^{5}$ Die Facharbeiterschaft stammte oft noch aus den Reihen der anglophonen „Natives“ oder den Einwanderern der Zeit vor dem Bürgerkrieg. Angelernte und ungelernte Kräfte rekrutierten sich eher aus den Reihen der „neuen Einwanderung“. Die Mechanisierung und Arbeitsteilung der Industriearbeit machte Facharbeiter überflüssig. Sie wurden durch angelernte oder ungelernte Arbeiter ersetzt, die auch untereinander nationalistische und rassistische Vorurteile pflegten. Carnegies Manager Henry Clay Frick stellte 1884 Ungarn und Slawen als Streikbrecher in den Kohlegruben Pennsylvanias ein und als diese sechs Jahre später selbst streikten, ersetzte er sie durch Italiener. Die Mehrzahl der neuen und ungelernten Kräfte kam nach 1880 aus Süd- und Osteuropa, während die alten Facharbeiter eher aus Nord- und Westeuropa stammten. Sie kritisierten die Neuankömmlinge unter Verwendung rassistischer Stereotype. ${ }^{6}$

Die Ressentiments dieses irischen Arbeiters waren typisch und unterstrichen die Allgegenwart rassistischer Praktiken und Diskurse in der sich formierenden Industriearbeiterschaft. Ethnische und religiöse Unterschiedlichkeit wurde in der Regel rassifiziert, d.h. als Eigenschaften einer eigenen „Rasse“ wahrgenommen und beschrieben. Selbst die gebildete Elite sprach damals von der polnischen „Rasse“ oder der ,jüdischen Rasse“. Dabei galt die Regel, dass jede Gruppe von Neuankömmlingen unterhalb der bereits im Lande lebenden Menschen angesiedelt war. Neuankömmlinge von der europäischen „Peripherie“ wurden als unassimilierbare Herumtreiber konstruiert, die politisch und sozial korrumpiert waren und auf keinen Fall in die Gewerkschaft aufgenommen werden sollten (Critical Juncture). ${ }^{7}$

5 Siehe Tabelle 9. Man muss sich verdeutlichen, dass ein Durchschnittslohn von 420 Dollar im Jahr (1899) bedeutete, dass eine Familie mit einem Dollar und 15 Cents am Tag auskommen musste, wenn der Industriearbeiter der alleinige Verdiener war. In die Lohnsummen eingeschlossen sind allerdings auch die Löhne für Frauen und Kinder. Quelle: Historical Statistics of the United States, Band 2, Series P 1-12, S. 666.

6 Zitiert in: Montgomery, The Fall of the House of Labor, S. 82.

7 Montgomery, The Fall of the House of Labor, S. 82. 
Die Iren, die die Italiener so stark verurteilten, hatten sich nur eine Generation zuvor ähnliche Invektiven als faule Untermenschen anhören müssen. Der Sozialdarwinismus war anschlussfähig sowohl an die mitgebrachten nationalistischen Vorurteile wie an die rassistischen Diskurse der bereits in den USA lebenden Gruppen. Nach der Überzeugung eines Großteils der sich als Weiße begreifenden Amerikaner und Amerikanerinnen standen die Weißen an der Spitze der amerikanischen Kultur und Zivilisation. Wer aber konnte als Weißer gelten? Die soziale Konstruiertheit dieser Kategorie ist nirgendwo sichtbarer als in dem Statement eines irischen Schauerarbeiters, der angab, er selbst beschäftige nur „Weiße“ zum Verladen der Fracht im Hafen, wobei er Polen und Italiener ausdrücklich in dieser Gruppe ausschloss. ${ }^{8}$ Diese Exklusion war u.a. auch gegen afroamerikanische Schauerleute gerichtet, die am untersten Ende der Wertschätzung standen, möglicherweise auch, weil sie sich oft als Streikbrecher missbrauchen ließen. ${ }^{9}$

Die deutlichste rassistische Diskriminierung am Arbeitsplatz war gegen $A f$ rican Americans und Menschen asiatischer Herkunft gerichtet. Wie andere Menschen aus der agrarischen Peripherie fanden afroamerikanische Männer Arbeit als unterbezahlte Hilfskräfte in der Industrie der Städte. Frauen und Mädchen arbeiteten in den Haushalten der weißen Mittelschicht als Zugehfrauen, Kindermädchen oder Köchinnen. Als Abkömmlinge von Versklavten oder als Menschen, die die Sklaverei noch am eigenen Leib erfahren hatten, war ihnen die Akkordarbeit in der Gruppe nicht unbekannt.

Diese Form der Diskriminierung etablierte das zweigliedrige Arbeitssystem, das in den USA seit dem 19. Jahrhundert endemisch ist. In der oberen „Etage“, die vom CEO bis zum hochqualifizierten Angestellten oder Techniker reicht, fanden sich mehrheitlich weiße Männer. In der zweiten Etage, die alle niederen Angestellten, Fabrikarbeiter, Farmkräfte und die Angehörigen von Berufsgruppen, die Gefahren und Schmutz am Arbeitsplatz ausgesetzt sind, fanden sich über-

8 Yanow, Dvora. Constructing „Race“ and „Ethnicity“ in America: Category-Making in Public Policy and Administration. Armonk, NY: M.E. Sharpe, 2003, S. 58.

9 Nelson, Bruce. Divided We Stand: American Workers and the Struggle for Black Equality. Princeton, NJ: Princeton University Press, 2001, S. 19, 23-25. Weiterführende Literatur zu den Whiteness Studies viz. Garner, Steve. Whiteness: An Introduction. Milton Park, Abingdon, Oxon, New York: Routledge, 2007. Ignatiev, Noel. How the Irish Became White. New York: Routledge, 2008. Carter, Julian. The Heart of Whiteness: Normal Sexuality and Race in America, 1880-1940. Durham, NC: Duke University Press, 2007. Gómez, Laura E. Manifest Destinies the Making of the Mexican American Race. New York: New York University, 2007. Moreton-Robinson, Aileen, Casey, Maryrose und Nicoll, Fiona Jean. Transnational Whiteness Matters. Lanham, MD: Lexington Books, 2008. Nevels, Cynthia Skove. Lynching to Belong: Claiming Whiteness through Racial Violence. College Station, TX: Texas A\&M University Press, 2007. 
proportional viele Angehörige ethnischer Minderheiten, African Americans und Frauen. ${ }^{10}$

Am untersten Ende - sozusagen im Keller - standen jedoch die African Americans, die als Strafgefangene unter irgendeinem Vorwand verhaftet worden waren und nun als Arbeitskräfte verliehen wurden, wobei sie keinen Lohn bezogen und ihre Haftstrafe nach Belieben durch Hinzufügung neuer fadenscheiniger Gründe verlängert werden konnte. Diese Form der Gefangenenarbeit, das convict lease system, erlaubte es Privatpersonen, unter dem Deckmantel des Justizsystems, eine neue Form der Sklaverei einzuführen. Sehr oft verrichteten schwarze Gefangene, in Chain Gangs aneinander gekettet, Arbeit beim Bau der Straßen oder bei der Terpentingewinnung im Süden, bewacht von bewaffneten Wächtern im Dienste des Sheriffs, verurteilt unter dem Vorwand der „Landstreicherei“. Ein Afroamerikaner, der seine Schulden während eines dreijährigen Aufenthalts in einem der Gefängnisse abarbeiten musste, fasste das System der Chain Gang folgendermaßen zusammen: „[...] call it slavery, peonage, or what not, the truth is we lived in a hell on earth [...]“11

Der gegen Menschen aus Asien gerichtete Rassismus konzentrierte sich vor allem auf den Westen der USA, den hier lagen die größten chinesischen Communities. Japanische Einwanderer und Einwandererinnen waren wegen ihrer kleineren Zahlen zunächst noch nicht betroffen - 1890 waren erst 2.000 Japaner und Japanerinnen in die USA eingewandert. Im Falle der chinesischen Arbeitskräfte kam es zu einer eigenartigen Verquickung von Rassismen mit der Rhetorik der Arbeiterbewegung. Chinesen in den Goldminen, beim Eisenbahnbau, in den Schuhfabriken und Wäschereien wurden als „Werkzeuge des Kapitals“ diffamiert, die von den Unternehmern angeworben würden, um Lohndumping zu betreiben. An der Westküste, wo der Strukturwandel von einer vor allem auf die Goldindustrie ausgerichteten Wirtschaft hin zu einer stärker diversifierten Ökonomie in der Krise von 1873 Probleme schuf, wurden chinesische Arbeitskräfte für die Wirtschaftsprobleme verantwortlich gemacht. Politiker, Journalisten, geistliche und vor allem selbsternannte „Arbeiterführer“ vom Schlage des irischen Einwanderers Dennis Kearney (1846? -1907) setzten sich mit dem Slogan „The Chinese must go!“ für eine Ausweisung der Chinesen aus Kalifornien ein. Er gründete 1878 die kurzlebige Workingmen's Party of California, eine nationalistische und in Worten sozialistische Gruppierung, die man durchaus als Vorläuferin faschistischer Bestrebungen bezeichnen kann, die aber nach 1880 mit der Verbesserung der

10 Better, Shirley Jean. Institutional Racism: A Primer on Theory and Strategies for Social Change. Lanham, MD: Rowman \& Littlefield Publishers, 2008, S. 65-67.

11 Katzman, David M. und Tuttle, William M. Plain Folk: The Life Stories of Undistinguished Americans. Urbana, IL: University of Illinois Press, 1982, S. 159. 
wirtschaftlichen Lage an Bedeutung verlor. Mit der Verabschiedung des Chinese Exclusion Act (1882) begann ein bis 1943 wirksamer Ausschluss der chinesischen Einwanderung und wurde der Grundstein gelegt für eine generelle Quotierung der Einwanderung nach rassistischen Gesichtspunkten. ${ }^{12}$ Unterstützt wurden sie dabei auch von der Arbeiterbewegung, die sich massiv für die Passage des Chinese Exclusion Act einsetzte. So unterstützte die American Federation of Labor unter ihrem Präsidenten Samuel Gompers die Annahme dieses Gesetzes, mit Argumenten, die auf die „Rettung der Männlichkeit“ weißer Arbeit und den Schutz weißer Frauen vor Verlust ihres Arbeitsplatzes hinausliefen. ${ }^{13}$ Hier liegt eine weitere Kreuzung (Critical Juncture) auf dem Pfad der historischen Entwicklung hin zu einer Verfestigung des Systems (Lock-in).

\subsection{Der große Eisenbahnstreik von 1877}

Der Eisenbahnstreik von 1877 galt allen Beteiligten als Fanal. Die Unternehmer und die Regierung sahen in ihm einen Ausbruch von ungeahnter Radikalität, die als Ergebnis der Machinationen von ausländischen Agitatoren und Kommunisten interpretiert wurde. Die Arbeiter und die Gewerkschaften wurden sich ihrer Stärke bewusst und die Gewerkschaftsbewegung nahm nach 1877 einen Aufschwung, der die Klassenfrage schärfer konturierte und Diskurse anschob, in deren Zentrum Begriffe wie Gerechtigkeit und Ausbeutung standen.

12 Saxton, Alexander. The Indispensable Enemy: Labor and the Anti-Chinese Movement in California. Berkeley, CA: University of California Press, 1995. Finzsch, Norbert. ,Einige unserer Fabriken sind geschlossen worden und andere haben ihre Arbeiter entlassen': Die Rezession der 1870er Jahre und die Industriearbeiter San Franciscos - Eine Analyse der Arbeitsstättenzählungen von 1870 und 1880. Amerikastudien/American Studies. 1987; (31):453-468. Der CEA hatte zunächst eine Laufzeit von zehn Jahren, wurde 1892 wieder um zehn Jahre verlängert und galt ab 1902 ohne zeitliche Begrenzung bis 1943. Anlässlich der Beratungen zur Perpetuierung des Gesetzes hielt und veröffentlichte Samuel Gomper 1901 seine notorische Meat vs. Rice-Rede, die zur Verlägerung des Gesetzes ad infinitum beitrug. American Federation of Labor. Some Reasons for Chinese Exclusion. Meat vs. Rice. American Manhood against Asiatic Coolieism. Which Shall Survive? Washington, DC: Government Printing Office, 1902.

13 Calavita, Kitty. The Paradoxes of Race, Class, Identity, and „Passing“: Enforcing the Chinese Exclusion Acts, 1882-1910. Law \& Social Inquiry. 2000 Winter; 25 (1):1-40. Jung, Moon-Ho 1969. Outlawing „Coolies“: Race, Nation, and Empire in the Age of Emancipation. American Quarterly. 2005 Sep; 57(3). 
Es begann am 14. Juli 1877, dem Jahrestag der Französischen Revolution von 1789. Der ungeplante Streik brach in Martinsburg, West Virginia, aus. ${ }^{14}$ Es war kein Zufall, dass sich der Streik in der Eisenbahnindustrie entzündete, doch reichten die Probleme weit über die Eisenbahnen hinaus. Auf die Wirtschaftskrise von 1873 war eine lange Phase der ökonomischen Kontraktion gefolgt, die drei Millionen Menschen arbeitslos machte. Diejenigen, die ihre Arbeit behalten konnten, mussten erhebliche Lohnkürzungen hinnehmen. Familien fielen unter das Existenzminimum und Suppenküchen in den großen Städten linderten die größte Not. Als ein Zigarrenmacher aus Cincinnati, Ohio, gefragt wurde, wie er seine fünfköpfige Familie mit einem Wochenlohn von fünf Dollar durchbrächte, antwortete er: „I don't live. I am literally starving. We get meat once a week, the rest of the week we have dry bread and black coffee. “15

Die Streikwelle hatte sich bis zum 16. Juli auf die gesamte Baltimore and Ohio Railroad (B\&O) in West Virginia verteilt und hatte sich von dort aus schnell entlang der großen Schienennetze ausgebreitet. 100.000 Eisenbahner waren schließlich in den Ausstand getreten. Bestreikt wurden vor allem die B\&O, die Pennsylvania Railroad und die New York Central von Baltimore bis San Francisco. Die Streikenden beklagten sich über fortgesetzte Lohnreduzierungen. Sie wurden von vielen anderen Lohnabhängigen unterstützt, denen klar war, was Lohnkürzungen auf dem Höhepunkt einer Wirtschaftskrise bedeuteten. Sogar die Milizen der Bundesstaaten weigerten sich vielfach, gegen die Streikenden auszurücken. In Reading, PA, weigerte sich die Miliz, das Feuer auf die Eisenbahner zu eröffnen: „We may be militiamen, but we are workmen first.“16

Die Lasten der Wirtschaftskrise trafen die Arbeiterklasse schlimmer als alle anderen Gruppen. Die Aktiengesellschaften entließen Beschäftigte, um Kosten zu sparen. Lohnkürzungen wurden flächendeckend durchgesetzt. Dennoch wurden Dividenden an die Anteilseigner gezahlt. Die Baltimore and Ohio Railroad (B\&O) kündigte eine zehnprozentige Lohnabsenkung an und zwar ausgerechnet in derselben Woche, in der sie den Aktionären eine zehnprozentige Dividende versprochen hatten. Die Bremser in West Virginia, die schon dreimal eine Lohn-

14 Bruce, Robert V. 1877, Year of Violence. Chicago: I.R. Dee, 1989. Foner, Philip Sheldon. The Great Labor Uprising of 1877. New York: Monad Press, 1977. Stowell, David O. The Great Strikes of 1877. Urbana, IL: University of Illinois Press, 2008. Stowell, David O. Streets, Railroads, and the Great Strike of 1877. Chicago, IL: University of Chicago Press, 1999.

15 Roger-Cooper, Justin. Blood or Bread: The 1877 General Strike and Anglophone Food Riots. Academia.edu. [Web Page]: https://www.academia.edu/2997605/2012_ASA_Conference_Paper_ on_1877_General_Strike. Gesehen am 6. Februar 2015, n.p.

16 Foner, Philip Sheldon. History of the Labor Movement in the United States. New York: International Publishers, 1947, S. 469. 
kürzung hatten hinnehmen müssen und deren Lohn von 70 Dollar auf 30 Dollar im Monat gesunken war, legten darauf ihre Arbeit nieder. Ein Arbeiter erläuterte die Gründe für den Streik:

We eat our hard bread and tainted meat two days old on the sooty cars up the road, and when we come home, find our children gnawing bones and our wives complaining that they cannot even buy hominy and molasses for food. ${ }^{17}$

Die Eisenbahnunternehmen weigerten sich beharrlich, in Verhandlungen einzutreten, weil sie insgeheim hofften, Bundestruppen und Miliz würden dem Streik ein Ende bereiten. Die Gouverneure von acht Bundesstaaten erklärten, bei dem Streik handele es sich um einen Aufstand und verlangten den Einsatz der USArmee. Präsident Rutherford B. Hayes, der seine Wahl in der umstrittenen Wahl von 1876 dem Einfluss des Generaldirektors der Pennsylvania Railroad Thomas A. Scott verdankte, zögerte nur kurz, bevor er den Einsatzbefehl für die Armee unterschrieb. ${ }^{18}$ Als die Armee eintraf, war das Schlimmste vorüber. Die Armee betätigte sich im Folgenden als Streikbrecherin, indem sie den Zugverkehr wieder in Gang brachte, Züge mit Arbeitswilligen zum Einsatzort eskortierte und die Zuglinien sicherte.

Der Streik von 1877 war spontan und schlecht organisiert angegangen worden. Dennoch verbreitete sich Panik unter den Regierungsmitgliedern und den Besitzenden. Ein Schuldiger musste gefunden werden: Schnell einigte man sich auf die 1876 gegründete kleine Workingmen's Party und sagte einen allgemeinen Aufstand voraus. Unbeschadet der Tatsache, dass sich diese marxistisch beeinflusste Partei im Wesentlichen aus Immigranten zusammensetzte und in einen marxistischen und einen lassalleanischen Flügel zerfiel, wurde ihr die Verantwortung für die Unruhen gegeben. Dabei hatte die lassalleanische Parteiführung die Parole ausgegeben, sich am Streik nicht zu beteiligen. ${ }^{19}$

„Any hour the mob chooses it can destroy any city in the country-that is the simple truth“, schrieb der Journalist und zukünftige US-Außenminister John Milton Hay (1838-1905) seinem schwerreichen Schwiegervater Amasa Stone $(1818-1883) .{ }^{20}$ Hay war so aufgebracht über den Streik, dass er sogar einen Ro-

17 July 20, 1877 edition of the Baltimore American.

18 Nelson, Scott Reynolds und Sheriff, Carol. A People at War: Civilians and Soldiers in America's Civil War, 1854-1877. New York: Oxford University Press, 2007, S. 327.

19 Kipnis, Ira. The American Socialist Movement, 1897-1912. New York: Monthly Review Press, 1972, S. 9. Foner, Philip Sheldon. The Workingmen's Party of the United States: A History of the First Marxist Party in the Americas. Minneapolis, MN: MEP Publications, 1984, S. 76-80.

20 Thayer, William Roscoe. The Life and Letters of John Hay. Boston and New York: Houghton Mifflin Company, 1915, 2 Bände, Band 2, S. 2. 
man über ihn schrieb. ${ }^{21}$ Die New York Times veröffentlichte Artikel über die „dangerous classes“, und der Independent hatte eine Patentlösung für den Umgang mit streikenden Arbeitern parat, Kugeln und Bajonette. ${ }^{22}$

Zwei Wochen im Sommer des Jahres 1877 war das Kabinett von Präsident Rutherford B. Hayes fast ausschließlich damit beschäftigt, die größte Rebellion seit Ende des Bürgerkriegs niederzuschlagen. Der Präsident traf sich täglich mit seinen Ministern, plante militärische Strategien und saß nachts noch lange am Schreibtisch, wo er sich dem Aktenstudium und der Auswertung der Berichte seiner Generäle widmete. In neun Staaten ließ er das Militär ausrücken, verlegte Kriegsschiffe an die Mündung des Potomac, um die Hauptstadt zu schützen, und drohte damit, das Kriegsrecht zu verhängen.

Der Streik der Bremser auf der B\&O war nur der Auslöser für einen Ausstand anderer Eisenbahnarbeiter im ganzen Land. In den großen Eisenbahnknotenpunkten Chicago, St. Louis, Kansas City und San Francisco war die Streikbereitschaft besonders hoch. Innerhalb weniger Tage hatten mehr als 100.000 Eisenbahner die Arbeit niedergelegt. Ihnen folgten bald andere Beschäftigte. Bald befanden sich mehr als eine halbe Million Menschen im Ausstand. Gebäude der Eisenbahngesellschaften wurden zerstört oder in Brand gesteckt. Schienen und Straßen wurden blockiert. Von West Virginia griff der Streik nach Maryland über. Die eingesetzte Nationalgarde des Staates wurde von Bewohnern der Stadt Baltimore angegriffen. Es kam zu heftigen Straßenkämpfen, bei denen zehn Menschen ums Leben kamen und 25 verletzt wurden. Die Milizsoldaten wurden bis zum 22. Juli von Streikenden in den Eisenbahndepots von Camden eingeschlos-

21 Hay, John Milton. The Bread-Winners: A Social Study. New York: Harper \& Brothers, 1884 22 The Independent, zitiert in Mead, Sidney E. American Protestantism since the Civil War. II. From Americanism to Christianity. The Journal of Religion. 1956 Apr; 36 (2):67-89, S.73. Die „gefährlichen Klassen“ waren fester Bestandteil des Diskurses über die Arbeiterklasse der USA, Frankreichs und Englands in den Jahren vor und nach 1877. Moon, Michael. „The Gentle Boy from the Dangerous Classes“: Pederasty, Domesticity, and Capitalism in Horatio Alger. Representations. 1987 Summer; (19):87-110. Alexander von Hoffman. An Officer of the Neighborhood: A Boston Patrolman on the Beat in 1895. Journal of Social History. 1992 Winter; 26 (2):309-330. Adshead, Joseph. On Juvenile Criminals, Reformatories, and the Means of Rendering the Perishing and Dangerous Classes Serviceable to the State. Manchester: Printed by J. Harrison and Son, 1856. Brace, Charles Loring. The Dangerous Classes of New York and Twenty Years' Work among Them. New York: Wynkoop \& Hallenbeck, 1872. Carpenter, Mary. Reformatory Schools, for the Children of the Perishing and Dangerous Classes, and for Juvenile Offenders. London: C. Gilpin; etc., etc., 1851. Frégier, Honoré Antoine. Des classes dangereuses : De la population dans les grandes villes. Paris: Chez J.-B. Baillière, 1840, 2 Bände. Zu Frankreich siehe Chevalier, Louis. Laboring Classes and Dangerous Classes in Paris during the First Half of the Nineteenth Century. New York: Howard Fertig, 2000. 
sen, so dass der Präsident US-Truppen, darunter die Marineinfanterie, zu ihrem Entsatz schicken musste.

Besonders schlimm ging es in Pennsylvania und hier insbesondere in Pittsburgh zu. Die Pennsylvania Railroad Company (PRC) hatte nach der Panic von 1873 die Löhne um zehn Prozent reduziert und im Juni 1877 wurden die schon abgesenkten Löhne um weitere zehn Prozent gekürzt. Betroffen von den Kürzungen waren auch die Beschäftigten der Eisenbahngesellschaften unter der Kontrolle der PRC, deren Heimatbahnhöfe allesamt in Pittsburgh lagen. Der Präsident der PRC Thomas Alexander Scott (1823-1881) traf sich mit einer Delegation der Eisenbahner und erklärte ihnen in dürren Worten, die Lohnkürzungen seien unverzichtbar. Der Wortführer der Arbeiter war Robert A. Ammon, ein 24-jähriger Bremser, der sich für einen Streik einsetzte und die Trainsmen Union organisierte, die alle Eisenbahnarbeiter aufnahm, also nicht nach Berufsgruppen differenzierte. ${ }^{23}$ Der Streik weitete sich rasch aus, auch weil das mittlere Management die Streikenden respektlos behandelte. ${ }^{24}$ Scott schlug vor, gewaltsam gegen die Streikenden vorzugehen. Die örtliche Polizei und Miliztruppen aus Pittsburgh weigerten sich jedoch, auf die Arbeiter zu schießen. Milizregimenter aus Philadelphia, die mit Schnellfeuerwaffen ausgestattet waren, wurden angefordert. Die Miliz des Staates eröffnete das Feuer und ging mit aufgesetztem Bajonett gegen die Streikenden vor. 20 tote Arbeiter blieben auf dem Schlachtfeld zurück, 29 weitere wurden schwer verletzt.

Wenn die Regierung gehofft hatte, die unangemessene Härte des Militäreinsatzes würde abschreckend wirken, so sah sie sich getäuscht. Die Milizionäre wurden zurückgeworfen, mussten sich in einem Lokschuppen verschanzen. 39 Gebäude der Eisenbahn gingen in Flammen auf, 104 Lokomotiven wurden zerstört und zahlreiche Fracht- und Passagierwaggons sabotiert. Der angerichtete Schaden belief sich nach Schätzungen auf fünf Millionen Dollar. ${ }^{25}$ Die Streikenden hatten sich nun auch bewaffnet, ja sie verfügten sogar über eine Kanone. Am 22. Juli wagten die belagerten Milizsoldaten einen Ausbruch aus dem Lokschuppen, schossen sich den Weg frei und flüchteten aus der Stadt. 20 weitere Tote, einschließlich einiger getöteter Soldaten, ließen sie zurück. ${ }^{26}$ Der Untersuchungsbericht des Parlaments von Pennsylvania unterstrich die Tatsache, dass eine große Anzahl von Frauen an den Aktionen gegen das Militär und die Ei-

23 Churella, Albert J. The Pennsylvania Railroad: Building an Empire, 1846-1917. Philadelphia, PA: University of Pennsylvania Press, 2013, Band 1, S. 480.

24 Commonwealth of Pennsylvania, Senate und House. Report of the Committee Appointed to Investigate the Railroad Riots in July 1877. Harrisburg, PA: Lanes and Hart, 1878, S. 4.

25 Commonwealth of Pennsylvania, Senate und House. Report of the Committee, S. 19.

26 Commonwealth of Pennsylvania, Senate und House. Report of the Committee, S. 12-15. 
senbahn beteiligt gewesen seien und hob die Militanz der Frauen hervor. ${ }^{27}$ Präsident Hayes befahl nun den Einsatz der regulären Armee. Auch in Philadelphia konnte der Aufstand nur mithilfe von US-Truppen niedergeschlagen werden. In Reading, Pennsylvania, dem Standort der Philadelphia and Reading Railroad, hatte schon im April des Jahres ein Streik der Eisenbahner begonnen. Hier tötete die Miliz am 23. Juli 1977 im Laufe des „Reading Railroad Massacre“ zehn Menschen. ${ }^{28}$ Zwei Tage später kam es zum Shamokin-Aufstand, bei dem 1.000 Männer und Jugendliche, die mehrheitlich in den Kohlegruben der Umgebung arbeiteten, das Eisenbahndepot der Reading Railroad besetzten und Eigentum der Gesellschaft zerstörten. Die Kohlekumpel waren erbost über das Angebot der Stadt Shamokin, ihnen einen Dollar pro Tag für öffentliche Arbeiten zu zahlen. Der Bürgermeister Shamokins, Besitzer einer Kohlegrube, setzte seine eigene Bürgerwehr ein, die an der Tötung von 14 Menschen beteiligt war. Ähnliche Szenen spielten sich in Scranton, PA, ab, wo die City Guard, eine Bürgerwehr, im Interesse der Unternehmer gegen die Streikenden einschritt und auf am Streik teilnehmende Menschen schoss. ${ }^{29}$

In Illinois kam es zu weitgehendem Stillstand der Eisenbahnen und damit zur Lahmlegung des gesamten Zugverkehrs in westlicher Richtung. Kohlekumpel im ganzen Staat beteiligten sich an den Aktionen und in Chicago konnte die Workingmen's Party Massendemonstrationen abhalten, an denen sich 20.000 Menschen beteiligten. Gerichte verurteilten verhaftete Arbeiter und steckten sie ins Gefängnis. Wie an anderen Orten wurde der Streik auch in Chicago mit der Hilfe einer 5.000 Köpfe zählenden Bürgerwehr gewaltsam niedergeschlagen, bevor die Miliz und die Armee eingreifen konnten. Am 25. Juli kam es zur „Schlacht am Viaduct“. Bei diesen und anderen Kampfhandlungen kamen 30 Menschen, die meisten von ihnen deutsche und „böhmische“ Einwanderer, ums Leben. ${ }^{30}$

Aber auch in Saint Louis, Missouri, streikten die Eisenbahner. East Saint Louis auf der anderen Seite des Missouri gehörte noch zum Bundessstaat Illinois. Hier kam es zur Arbeitsniederlegung und die Workingmen's Party von Missouri griff in den Streik ein, indem sie die Brücke über den Fluss überquerten und den

27 Commonwealth of Pennsylvania, Senate und House. Report of the Committee, S. 15.

28 Commonwealth of Pennsylvania, Senate und House. Report of the Committee, S. 27.

29 Allgemein zur Gewalt im Laufe des Strikes siehe Bellesiles, Michael A. 1877: America's Year of Living Violently. New York: New Press. Distributed by Perseus Distribution, 2010. Zu Scranton, PA, aus Sicht der Gegner des Streiks Logan, Samuel Crothers. A City's Danger and Defense. Scranton, PA: J. B. Rodgers Printing Co., 1887. Zum Einsatz der Bürgerwehr gegen die Streikenden siehe S. $95-100$.

30 Green, James R. Death in the Haymarket: A Story of Chicago, the First Labor Movement, and the Bombing That Divided Gilded Age America. New York: Pantheon Books, 2006, S. 78-80. 
Streikenden so ihre Solidarität ausdrückten. ${ }^{31}$ In Missouri entwickelte sich daraufhin ein regelrechter Generalstreik, bei dem es um die Einführung des Achtstundentags und das Ende der Kinderarbeit ging. ${ }^{32} 3.000$ Armeesoldaten und 5.000 Polizisten wurden eingesetzt und töteten mindestens 18 Personen in Auseinandersetzungen in und um Saint Louis. Am 28. Juli eroberten diese Truppen das Weichenhaus der Eisenbahn zurück und verhafteten 70 sich darin aufhaltende Streikende.

Die Streikenden wurden sehr oft als Radikale, Kommunisten oder Anarchisten denunziert. ${ }^{33}$ In St. Louis gab es zwar eine Organisation der 1. Marxistischen Internationale, jedoch war diese Gruppe zu schwach, um Einfluss auf das Geschehen zu nehmen. ${ }^{34}$ Auffällig waren xenophobe Untertöne, weil Deutsche oder österreichische Staatsbürger besonders häufig für die Ausschreitungen verantwortlich gemacht wurden. Am 4. September war alles vorbei. Präsident Hayes vermerkte schon am 5. August in seinem Tagebuch: „The strikes have been put down by force. “ [Hervorhebung im Original, M.H.] ${ }^{35}$

Auch wenn der Streik für die Arbeitenden im Lande schlecht ausging, blieb seine Langzeitwirkung beachtlich. Die Arbeiter hatten eine Lektion gelernt. Sie mussten sich besser organisieren. Gewerkschaftsführer Samuel Gompers (1850 1924) fasste die Wirkung des Streiks von 187750 Jahre später zusammen: „The railroad strike of 1877 was the tocsin that sounded a ringing message of hope to us all." ${ }^{36}$ Die Vorstände der Konzerne hatten auch etwas gelernt: Besser als Miliz oder Truppen eigneten sich private Detekteien zur Niederschlagung von Arbeitskämpfen.

Die Unruhen des Sommers 1877 verdeutlichten die Widersprüche, die die rasche Industrialisierung des Landes zu Tage gefördert hatte. Die Arbeitsbedingungen und die Löhne derjenigen, die jeden Tag riesige Werte schufen, blieben weit hinter den Möglichkeiten auch eines sich formierenden Kapitalismus zurück. Bisher wurde ihre Geschichte aus der Vogelperspektive erzählt. Es gilt nun, sie selbst zu Wort kommen zu lassen. Durch ihre Geschichte(n) wird es möglich sein,

31 Laurie und Cole, The Role of Federal Military Forces, S. 50 - 55.

32 Burbank, David T. Reign of the Rabble: The St. Louis General Strike of 1877. New York: A. M. Kelley, 1966.

33 Commonwealth of Pennsylvania, Report, S. 36. Logan, A City's Danger, S. 32, 40, 42, 109. 34 Pinkerton, Allan. Strikers, Communists, Tramps and Detectives. New York: G. W. Carleton \& Co, 1878. Roediger, David. America’s First General Strike: The St. Louis ,Commune` of 1877. Midwest Quarterly. 1989; (21):196-206.

35 Williams, Diary and Letters of Rutherford Birchard Hayes, Band 3, S. 440.

36 Filler, Louis. Muckraking and Progressivism in the American Tradition. New Brunswick, NJ: Transaction Publishers, 1996, S. 141. 
besser einzuschätzen, wie der Kapitalismus der Trusts und Oligopole die alte Arbeitswelt erschütterte und das Alltagsleben von Millionen Frauen und Männern radikal umformte. Die Flexibilisierung der neuen Arbeitswelt, die zunehmende Trennung von Kopf- und Handarbeit, die Segregation am Arbeitsplatz entlang ethnischer und rassifizierter „Grenzen“ und die Eroberung einzelner Bastionen von bisher männlichen Arbeitern vorbehaltenen Nischen auf dem Arbeitsmarkt durch Frauen kennzeichnen die Entwicklung des neuen Arbeitsmarktes. Die Arbeit wurde unpersönlicher und anonymer, wurde in größeren Gruppen und Zusammenhängen organisiert und der einzelne Arbeiter und die einzelne Arbeiterin verloren die Kontrolle über den Arbeitsprozess. Dazu muss man verstehen, dass industrielle Fertigung nach 1860 zunächst ein Prozess war, der der Überwachung und Leitung durch die Facharbeiter unterworfen war. In den Worten William Dudley Haywoods (1869-1928), des Sozialisten und Mitbegründers der Industrial Workers of the World: „The manager's brain are under the workman's cap. “37 Der Managementspezialist Frederick Winslow Taylor (1856-1915) beschrieb 1911 diese Struktur wortreicher und umständlicher, kam aber zu einem ähnlichen Ergebnis. $^{38}$

$\mathrm{Zu}$ den Arbeitern, die diese Form der Kontrolle ausüben konnten, gehörten die Eisengießer, Glasbläser, Fassbinder, die Maschinisten der Papiermaschinen, Lokomotivführer, Kesselmacher, Klempner, die Maschinisten an den Nähmaschinen in den großen Schuhfabriken, die Setzer und die Bergleute. ${ }^{39}$ Drei Prinzipien galten für diese Form der Produktion: 1) Die Arbeiter legten das Arbeitstempo selbst fest, fixierten eine Quote als sogenannten stint, unabhängig davon, ob sie gewerkschaftlich organisiert waren oder nicht. 2) Zur Produzentenethik dieser Arbeiter gehörte ein „männliches Auftreten“ gegenüber dem Vorgesetzten oder Fabrikbesitzer, aber 3) auch gegenüber den Kollegen am Arbeitsplatz. Dies schloss unter anderem die Einhaltung von geschriebenen oder ungeschriebenen Verhaltenskodizes am Arbeitsplatz ein. ${ }^{40}$

Diese Produzentenethik, die große Teile der amerikanischen Facharbeiterschaft noch um 1870 ausgezeichnet hatte, hatte sich überlebt. Stolz auf ihre Arbeit konnten nur noch wenige Facharbeiter oder Handwerker empfinden. Diese Form

37 Haywood, William Dudley und Bohn, Frank. Industrial Socialism. Chicago, IL: C. H. Kerr \& Company, Co-Operative, 1911, S. 25.

38 Taylor, Frederick Winslow. The Principles of Scientific Management. New York, London: Harper \& Brothers, 1911, S. $31 \mathrm{f}$.

39 Montgomery, David. Workers' Control of Machine Production in the Nineteenth Century. In: Leab, Daniel J. (Hg.). The Labor History Reader. Urbana, IL: University of Illinois Press, 1985, S. 107-131, S. 109.

40 Montgomery, David. Workers' Control of Machine Production, S. 111-114. 
der Entfremdung mag zu den Gründen gehört haben, die Teile der Arbeiterschaft gegen Ende der 1870er Jahre radikalisierte. Andererseits bereiteten die Gleichförmigkeit der Arbeit und die Einebnung der arbeitsinternen Hierarchien auch der Wahrnehmung kollektiver Interessen den Boden. Die von Präsident Hayes so gelobten nüchternen, intelligenten und fleißigen Arbeiter organisierten nicht nur die Streiks des Jahres 1877, sondern organisierten sich zunehmend in Gewerkschaften, die nicht mehr nur lokale Belegschaften einzelner Berufsgruppen zusammenschlossen, sondern versuchten, alle Arbeiter (und später auch Arbeiterinnen) des Landes einzugliedern. Es ging um wesentliche gewerkschaftliche Rechte wie das Recht auf Streiks und Organisation, verbesserte Arbeitsbedingungen, kürzere Arbeitszeiten und höhere Löhne. Angehörige der Mittelschichten zeigten sich besorgt über die Radikalisierung der Arbeiterschaft, fragten sich aber auch, was getan werden könne, um die schlimmsten Auswüchse des ungebremsten Kapitalismus zu beschneiden.

\subsection{Diversität und Spaltung der arbeitenden Bevölkerung}

Viele Familien der Arbeiterklasse lebten während des Gilded Age unterhalb der oder nahe an der Armutsgrenze. Das Auskommen der Familien hing von der Arbeit aller Familienmitglieder ab - unabhängig von Alter und Geschlecht. In einem System der Lohnarbeit war die bezahlte oder unbezahlte Arbeit von Frauen und Kindern essentiell wichtig, um das Überleben der Familie zu sichern. Die umgreifende Mechanisierung in den letzten zwei Jahrzenten des 19. Jahrhunderts erlaubte es, sehr viel mehr Kinder als zuvor in der Industrie zu beschäftigen, weil Körperkraft nicht mehr so entscheidend für den Arbeitseinsatz war. In den Kohlegruben hatten Kinder schon in der Mitte des 19. Jahrhunderts Arbeit gefunden. Ihre geringe Körpergröße hatte sie zu idealen Arbeitern in den engen Flözen gemacht. Auch in der Textilindustrie waren schon früh Kinder zum Einsatz gekommen. Im Maschinenzeitalter konnten Kinder genauso effektiv wie Männer arbeiten, ohne die Löhne zu erhalten, die Männern erlaubt hatte, eine Familie zu ernähren. ${ }^{41}$

Eine Sozialarbeiterin, die sich 1908 mit dem Problem der Kinderarbeit auseinandersetzte, bemerkte:

41 Zitiert in Abbott, Edith, A Study of the Early History of Child Labor in America. American Journal of Sociology 14 (July 1908):15-37, S.33, FN 74. Abbott zitiert den Report of the Massachusetts Bureau of Labor, 1871, S. 500. 
Turning from the extent of child labor to the conditions under which children worked, there is also much variation from state to state; but this variation is due rather to standards set by different manufacturing centers than to the interference of state laws. For child labor was practically unregulated in this country until after the Civil War. A few laws had been passed, but they remained on the statute books as so many dead letters. In Massachuset[t]s $\mathrm{s}$ a ten-hour law for children under twelve years was ineffectual, and not only in Massachusetts but in Connecticut and Rhode Island, laws which provided a low minimum of ,schooling ' went unenforced. The inevitable result of this lack of regulation was not only that very young children were worked, but that they were worked long hours, over time, and at night. $^{42}$

Versuche, die Kinderarbeit einzudämmen oder gar abzuschaffen, waren schon vor dem Bürgerkrieg unternommen worden. 1863 hatten verschiedene Saaten Gesetze erlassen, die die Arbeitszeit von Kindern begrenzte, doch wurden diese Gesetze nicht streng genug umgesetzt.

Die Südstaaten weigerten sich in der Regel, überhaupt gegen Kinderarbeit vorzugehen und Kinder wurden im großen Umfang in Fabriken des Südens eingestellt, darunter auch sechs- oder siebenjährige Kinder. In den Kohleminen der Nation, vor allem in den Appalachen, wurde kleine Jungen damit beschäftigt, Abraum und Verunreinigungen aus den Kohlen zu fischen, die an ihnen vorbei auf den Förderschütten transportiert wurden. ${ }^{43}$ Eine nationale Kommission zur Untersuchung der Kinderarbeit kam zu dem Schluss, dass mehr als 10.000 Kinder illegal in den Kohlegruben arbeiteten. ${ }^{44}$

Die Grubenindustrie jedoch war nicht der einzige Bereich, in dem sehr junge Kinder Verwendung fanden. Um die Jahrhundertwende arbeitete die absolute Mehrheit aller 7.000 Jungen, die in der Glasindustrie beschäftigt waren, an den extrem heißen Glasöfen. Hier war die Sterblichkeitsrate besonders hoch. ${ }^{45}$ Aktivisten und Aktivistinnen mobilisierten massiv gegen die Kinderarbeit. $\mathrm{Zu}$ den wichtigsten Aktivistinnen muss Florence Kelley (1859-1932) gerechnet werden, die als Marxistin, Feministin und Sozialarbeiterin schon im jungen Alter die Lage

42 Abbott, Edith, A Study of the Early History of Child Labor in America, American Journal of Sociology 14 (July 1908):15-37, S. 32f.

43 Hindman, Hugh D. Child Labor: An American History, Armonk, NY: M. E. Sharpe, 2002, S. $89-$ 120. Derickson, Alan. Black Lung: Anatomy of a Public Health Disaster. Ithaca, NY: Cornell University Press, 1998.

44 Lovejoy, Owen R. The Extent of Child Labor in the Anthracite Coal Industry. National Child Labor Committee (Hg.). Child Labor and the Republic. New York: American Academy of Political and Social Science, 1907, S. 35-49, S. 36.

45 Hoffman, Frederick Ludwig. Mortality from Respiratory Diseases in Dusty Trades (Inorganic Dusts). Washington, DC: Government Printing Office, 1918, S. 292-300. 
der Kinderarbeiter in den Glasfabriken hatte studieren können. ${ }^{46}$ Die Fotografen George Bretz (1842-1895) und Lewis Wickes Hine (1874-1940) sorgten mit ihren Bildern für Aufmerksamkeit und trugen so zur allmählichen Zurückdrängung dieses Übels bei. ${ }^{47}$

Gegen Ende des Jahrhunderts nahm die Kinderarbeit zu und stieg weiter bis zum Ersten Weltkrieg. Die Volkszählung von 1900 zeigt, dass 1.750.178 Kinder im Alter zwischen zehn und 15 Jahren auf den Farmen, in den Fabriken und Gruben arbeiteten, eine Zunahme von einer Million gegenüber 1870. 1870 waren 13,2 Prozent aller Kinder zwischen zehn und 15 Jahren angestellt, 1900 waren es 18,3 Prozent. ${ }^{48}$ Kinder zwischen zehn und 15 Jahren stellten mehr als 18 Prozent der arbeitenden Bevölkerung. Sieben Prozent aller abhängig Beschäftigten außerhalb der Landwirtschaft waren Kinder. Auch bei diesen Zahlen ist eine deutliche Zunahme gegenüber dem Bezugsjahr 1880 festzustellen. ${ }^{49}$

Kinderarbeit war auch innerhalb der Familie gang und gäbe. Es galt Feuerholz zu sammeln oder von den Güterwaggons oder Kohletendern heruntergefallene Kohlestücke aufzuheben. Diese Kohlesammler gingen ihrer Arbeit in der Regel als regelrechte Gangs nach. Kindergruppen machten die Städte unsicher, begingen kleinere Diebereien und machten Unsinn. Andere Kinder verkauften in den Straßen Obst und Gemüse, boten Zeitungen an oder putzten Schuhe. Zwar bestand in vielen Staaten eine Schulpflicht, doch war sie angesichts der wirtschaftlichen Situation vieler Familien schwer durchzusetzen. Bedienstete der Behörden, die die Anwesenheit der Schülerinnen und Schüler im Unterricht si-

46 Sklar, Kathryn Kish. Florence Kelley and the Nation's Work: The Rise of Women's Political Culture, 1830 - 1900. New Haven, CT: Yale University Press, 1995, S. 280 f. Sklar, Kathryn Kish, Schüler, Anja und Strasser, Susan. Social Justice Feminists in the United States and Germany: A Dialogue in Documents, 1885-1933. Ithaca, NY: Cornell University Press, 1998, S. 13-22. Kelley, Florence. Our Toiling Children. Chicago, IL: Women's Temperance Publication Association, 1889. Dies. The Working Child. Chicago, IL: Wm. C. Hollister \& Bro., printers, 1896.

47 Freedman, Russell. Kids at Work: Lewis Hine and the Crusade against Child Labor. New York: Houghton Mifflin Harcourt, 1998, S. 47-58 zu den Breaker Boys. Beck, Tom. George M. Bretz: Photographer in the Mines. Catonsville, MD: University of Maryland Baltimore County Library, 1977. Burgan, Michael. Breaker Boys: How a Photograph Helped End Child Labor. Mankato, MN: Compass Point Books, 2012.

48 Bremner, Children and Youth in America, Band 2, S. 605.

49 Carter, Susan und Sutch, Richard. Fixing the Facts: Editing of the 1880 U.S. Census of Occupations with Implications for Long-Term Labor Force Trends and the Sociology of Official Statistics. Historical Methods 29 (1996):5-24. 
cherstellen sollten (truant officers), kapitulierten vor dem Argument der Eltern, dass ihre Kinder zum Familieneinkommen beizutragen hatten. ${ }^{50}$

Um die Jahrhundertwende begannen auch immer mehr Frauen in der Industrie zu arbeiten. Auch sie erhielten, wie die Kinder, deutlich weniger Lohn. Waren Frauen in den 1870er Jahren typischerweise als Haushaltsgehilfen eingestellt gewesen, arbeiteten sie um 1890 als Fabrikarbeiterinnen und später auch als Sekretärinnen und in der Verwaltung. Der Census von 1870 führte 1,5 Millionen Frauen als Arbeiterinnen außerhalb der Landwirtschaft an. Bis 1900 stieg diese Zahl auf 4,9 Millionen an. 18,8 Prozent aller Industriearbeiter waren 1900 bereits Frauen. ${ }^{51}$

Tätigkeitsfelder und Arbeitsbedingungen der Frauen variierten abhängig von ihrer Hautfarbe und ethnischen Herkunft beträchtlich. ${ }^{52}$ Weiße verheiratete Frauen der Arbeiterklasse arbeiteten selten außerhalb des Heims. 1890 waren lediglich drei Prozent der verheirateten weißen Frauen außerhalb des Haushalts tätig. Trotzdem steuerten sie erheblich zum Familieneinkommen bei, indem sie unter anderem Untermieter aufnahmen. In vielen aus Italien eingewanderten Familien wurde Heimarbeit verrichtet, zum Beispiel die Herstellung von künstlichen Blumen. Auf diese Weise konnte das Familieneinkommen verbessert werden. ${ }^{53}$ Verheiratete Frauen brauchten auf diese Weise das Haus nicht zu verlassen, was es dem Ehemann erlaubte, die traditionelle patriarchale Wache über die „Familienehre“ aufrecht zu erhalten. ${ }^{54}$ Afroamerikanische Frauen arbeiteten hingegen unabhängig von ihrem Familienstand $\mathrm{zu}$ einem signifikant höheren Anteil außerhalb der Familie. Der Census von 1890 zeigt, dass 25 Prozent der verheirateten schwarzen Frauen außerhalb der Familie arbeiteten, oft als Köchinnen, Dienst- oder Kindermädchen für weiße Mittelschichtsfamilien. ${ }^{55}$ Unab-

50 Folks, Homer. Poverty and Parental Dependence as an Obstacle to Child Labor Reform. In: National Child Labor Committee (Hg.). Child Labor and the Republic. New York: National Child Labor Committee, 1907, S. 1-8.

51 United States, Historical Statistics, Band 1, Series D 75-84, S. 134.

52 McLennan, Kathleen A. Woman's Place: „Marriage“ in America’s Gilded Age. Theatre Journal. 1985 Oct; 37 (3):345-356. Tone, Andrea. Black Market Birth Control: Contraceptive Enterpreneurship [sic] and Criminality in the Gilded Age. The Journal of American History. 2000 Sep; 87 (2):435-459. Walkowitz, Daniel J. Working-Class Women in the Gilded Age: Factory, Community and Family Life among Cohoes, New York, Cotton Workers. Journal of Social History. 1972 Summer; 5 (4):464-490.

53 Cohen, Miriam. Workshop to Office: Two Generations of Italian Women in New York City, 1900 - 1950. Ithaca, NY: Cornell University Press, 1993, S. 101.

54 Cohen, Miriam. Workshop to Office, S. 34.

55 Palmer, Phyllis M. Domesticity and Dirt: Housewives and Domestic Servants in the United States, 1920 - 1945. Philadelphia, PA: Temple University Press, 1989. 
hängig von Hautfarbe und ethnischer Zugehörigkeit waren die Beiträge arbeitender Frauen substantiell für den Lebensstandard der betreffenden Familie. Ein Statistiker berechnete, dass um 190064 Prozent der Arbeiterfamilien vom Zusatzeinkommen der Frauen und Kinder abhängig waren. ${ }^{56}$

Während es auch im ausgehenden 19. Jahrhundert immer noch Handwerksbetriebe gab, in der Arbeit mit einem hohen Prestigewert versehen war, setzten sich doch immer stärker Arbeitsformen durch, die durch das Vordringen des Hochkapitalismus und der Großindustrie geprägt waren. Riesige Fabrikkomplexe mit angeschlossenen Industriesiedlungen, Kohleminen, Ölfelder, Sweatshops und Heimarbeit, Stückarbeit und Akkord, alle diese verschiedenen Umfelder beeinflussten auch die Art der Arbeit, die verrichtet wurde. Beim Straßenbau und beim Verlegen von Eisenbahnschienen dominierte noch die Handarbeit mit Schaufel und Spitzhacke - bevor auch hier verstärkt Maschinen zum Einsatz kamen. Diese Diversität ist nur schwer mit dem Rubrum „Arbeiterklasse“ zu beschreiben. Ich werde versuchen, dies anhand verschiedener Typen von Arbeit im Folgenden zu erläutern.

In ihrem Buch „China Men“ erzählt die chinesisch-amerikanische Romanschriftstellerin Maxine Hong Kingston (1940-) die Geschichte von Ah Goong, einem der gam saan haak (Reisenden zum Goldberg), der 1863 nach Kalifornien kam, als es für die Arbeit in den Goldminen schon zu spät war und deshalb bei der Central Pacific Railroad als Schienenarbeiter eingestellt wurde. ${ }^{57}$ Chinesische Eisenbahnarbeiter bauten die Eisenbahntrasse von San Francisco über die Sierra Nevada und durch die Mojave-Wüste nach Utah. Für weniger als einen Dollar am Tag hing Ah Goong in einem Korb über den Klippen des American River, legte Sprengkapseln und sprengte den Schienen einen Weg durch die Felsen und setzte Schaufel und Spitzhacke ein, um einen Tunnel durch den Granit zu schneiden. Die Eisenbahngesellschaft setzte das schwer handhabbare und gefährliche Nitroglyzerin ein und Ah Goong brachte die Ladungen an. Um sich etwas hinzuzuverdienen, riskierte er sein Leben und ging mitunter zurück in den Tunnel, um herauszubekommen, warum die Nitroglyzerinladungen nicht explodiert waren. Im Tunnel arbeitete er sieben Tage in der Woche acht Stunden lang. Die Eisenbahngesellschaft versuchte, den Arbeitstag auf zehn Stunden auszuweiten. Ah Goong und Zehntausend seiner chinesischen Kollegen traten 1867 in den Streik. Sie verlangten nicht nur die Rücknahme der Arbeitszeitverlängerung, sondern forderten auch den gleichen Lohn wie die irischen Arbeiter, die 40 Dollar im Monat erhielten, während die chinesischen Arbeitskräfte nur 30 Dollar in der

56 Piott, Steven L. Daily Life in the Progressive Era. Santa Barbara, CA: Greenwood, 2011, S. 70. 57 Kingston, Maxine Hong. China Men. New York: Vintage Books, 1989. 
Woche bekamen. Der Chefingenieur Charles Crocker sorgte für den Abbruch des Streiks, indem er die chinesischen Arbeiter von den Lebensmittellieferungen abschnitt. Der Streik war gescheitert. ${ }^{58}$

Das Leben beim Bau der Central Pacific war riskant. Die Männer starben in den Abhängen des American River, wenn die Seile rissen, die ihre Körbe in der Luft hielten oder wenn die Arbeiter es nicht mehr rechtzeitig aus dem Gefahrenbereich einer Sprengung schafften. Etliche Männer starben bei Sprengunglücken in den Tunnels. Die Eisenbahngesellschaft erhielt ja eine Landprämie für jede Meile gebauter Strecke und Crocker ließ die Männer in den Wintern der Jahre 1866 und 1867 hart arbeiten, um einen Tunnel durch den berüchtigten Donner Summit zu bauen. Im Winter 1867 fielen mehr als 44 Fuß Schnee. ${ }^{59}$ Erfrierungen und Schneeblindheit machten den Arbeitern schwer zu schaffen. Sprengungen lösten große Schneebretter, die die Männer lebendig unter sich begruben. Im Frühjahr schmolz der Schnee und gab den Körper eines Arbeiters frei, der sein Werkzeug noch im Tod umklammert hielt. Nun kann man entgegnen, bei Maxine Hong Kingstons Geschichte handele es sich um einen Roman und damit den Wahrheitsgehalt der Geschichte in Zweifel ziehen. Tatsache ist jedoch, dass die Autorin Fakt und Fiktion hier zu einem intensiven Narrativ verwoben hat und dass die historische Forschung dieses Narrativ im Großen und Ganzen als authentisch bestätigt hat. ${ }^{60}$

Ah Goong war in dieser Geschichte ein Glückspilz. Er lebte lang genug, um zu erleben, dass die Central Pacific 1869 Promontory Point in Utah erreichte, wo sich ihre Schienen mit denen der Union Pacific verbanden. Damit war die erste transkontinentale Eisenbahn der Vereinigten Staaten fertiggestellt.

In der Feierstunde anlässlich der Fertigstellung der Strecke hoben Redner der Eisenbahngesellschaft die vollbrachten Leistungen als „greatest monument of human labor" hervor und klopften sich auf die Schulter, weil sie sich zu einer derartigen Leistung fähig gezeigt hätten. ${ }^{61}$ Die chinesischen Arbeitskräfte wurden nicht erwähnt, obwohl über 80 Prozent der Arbeiter der Central Pacific aus China stammten. Die Fotografen, die das Einschlagen des goldenen Nagels in die Strecke

58 Arnesen, Eric. Encyclopedia of U.S. Labor and Working-Class History. New York: Routledge, 2007, 3 Bände, Band 1, S. 241-243.

59 Griswold, Wesley S. A Work of Giants: Building the First Transcontinental Railroad. New York: McGraw-Hill, 1962, S. 191.

60 Mancall, Peter und Johnson, Benjamin Heber (Hg.). Making of the American West: People and Perspectives. Santa Barbara, CA: ABC-CLIO, 2007, S. 166.

61 Saxton, Alexander. The Army of Canton in the High Sierra. The Pacific Historical Review. 1966 May; 35 (2):141-152, S. 152. 
aus Anlass der Fertigstellung dokumentierten, zeigten nur amerikanische Gesichter.

Ungelernte, hart arbeitende Männer wie Ah Goong bildeten das Rückgrat der amerikanischen Arbeiterklasse im 19. Jahrhundert. Ihre Arbeit mit Schaufel und Spitzhacke hatte sich bis auf die Einführung von Sprengmitteln wenig geändert. Dennoch stellten sie auch in den modernen Industriezweigen wie Stahl, Eisenbahnen und Bergbau einen nicht zu unterschätzenden Teil der Arbeitskräfte. Sie waren es, die die Eisenbahnlinien und Untergrundbahnen bauten und den East River untertunnelten, um die Fundamente der Brooklyn Bridge in den Boden zu versenken.

Am entgegengesetzten Ende des Spektrums befanden sich Facharbeiter wie der Puddler James J. Davis (1873-1947), ein Immigrant aus Tredegar in Wales. Puddler waren Facharbeiter, die im sogenannten Flammofenfrischen, einer besonderen Prozedur zur Herstellung von Schmiedeeisen aus Roheisen, die Produktion leiteten. Das besondere des Puddelverfahrens bestand darin, dass hier nicht mehr Holzkohle zum Einsatz kam, sondern die billigere Steinkohle verwendet werden konnte. Im Puddelofen wurde eine ausreichende Hitze erzeugt, um das meist als Barren vorliegende Roheisen zu schmelzen und es anschließend zu „frischen“, das heißt durch Oxidation den Gehalt von Kohlenstoff, Phosphor und Schwefel zu senken. Während das flüssige Eisen durch Oxidation allmählich Kohlenstoff verlor, stieg sein Schmelzpunkt. Obwohl die Temperatur im Ofen gleich blieb, wurde das Metall immer steifer, bis es verklumpte und dem Ofen entnommen werden konnte. ${ }^{62}$

In der Feuerkammer des Ofens wurde billige Steinkohle verbrannt, während der Arbeitsraum so weit wie möglich luftdicht verschlossen war. Dadurch schmolzen die in der Mulde des Arbeitsraums liegenden 200 bis 250 kg RoheisenBarren. Die Feuerbrücke verhinderte, dass das Eisen unerwünschte Bestandteile der Kohle wie vor allem Schwefel aufnahm, der es unbrauchbar gemacht hätte. Der für die Oxidation erforderliche Sauerstoff wurde nicht durch Gebläse zugeführt, sondern stammte aus der an Sauerstoffverbindungen reichhaltigen Schlacke. Der Puddler musste dazu das Roheisen mit der auf ihm schwimmenden Schlacke ständig mit einer langen Eisenstange umrühren, um den Kohlenstoff zu oxidieren. Gelegentlich musste die Stange ausgewechselt werden, bevor sie weich wurde. Infolge der Oxidation bildeten sich Klumpen von Eisen, die der Puddler

62 Die Abhandlung zum Puddeln beruht auf dem sehr informativen Wikipediaartikel zum Puddelverfahren, der in weiten Teilen die beste auf Deutsch verfügbare Darstellung zum Thema zitiert: Paulinyi, Ákos. Das Puddeln: Ein Kapitel aus der Geschichte des Eisens in der industriellen Revolution. München: Oldenbourg; 1987, S. 107-130. Wikipediaartikel ist unter https://de.wikipe dia.org/wiki/Puddelverfahren auffindbar. Gesehen am 13.3.2015. 
in etwa 40 Kilogramm schwere Kugeln zusammendrückte, aus denen sich blumenkohlförmige „Luppen“ oder Eisenschwämme bildeten. Passte der Puddler nicht auf, so konnten die Luppen auseinanderfallen, so dass sie erneut bearbeitet werden mussten. Die Luppen wurden zur Feuerbrücke geschoben, dem heißesten Ort in der Mulde, wo sie bei geschlossener Arbeitsöffnung für vier bis sechs Minuten der größtmöglichen Hitze ausgesetzt wurden. Anschließend wurde die Klappe des Arbeitsraums geöffnet, die Eisenschwämme mit einer Zange entnommen und über den Hallenboden des Hüttenwerks zum Dampfhammer geschleppt oder in Loren gefahren. Die Menge und die Qualität des erzeugten Schmiedeeisens hingen vom Geschick und der Kraft des Puddlers ab. Es war dies ein Beruf, der Erfahrung, Kraft und Intelligenz erforderte. Schon mit elf Jahren hatte James Davis in der Eisenfabrik in Sharon, Pennsylvania, gearbeitet und war mit 16 Jahren zum Meister befördert worden. Davis verglich seine Arbeit am Puddelofen mit Kuchenbacken.

I am like some frantic baker in the inferno kneading a batch of iron bread for the devil's breakfast. My spoon weighs twenty-five pounds, my porridge is pasty iron, and the heat of my kitchen is so great that if my body was not hardened to it, the ordeal would drop me in my tracks. ${ }^{63}$

Puddler konnten sieben Dollar am Tag verdienen - vorausgesetzt es gab Arbeit. Doch oft gab es keine Aufträge. Das Eisengeschäft der frühen Jahre war ein Saisongeschäft und eine stetige Anstellung über das ganze Jahr war eher die Ausnahme denn die Regel. Hinzu kamen die Rezessionen nach 1873 und 1893, die auch Spezialisten wie Davis hart trafen. In den 1890ern gehörte er zu einer wachsenden Gruppe von Wanderarbeitern, die auf der Suche nach Arbeit im Land umherirrten. Selbst so gut ausgebildete Handwerker wie Davis waren Konjunkturschwankungen schutzlos ausgeliefert. Hatten sie wegen Arbeitslosigkeit, Krankheit oder Arbeitsunfällen kein Einkommen, waren sie und ihre Familien der Armut überlassen. Es gab weder eine Unfallversicherung und Krankenversorgung noch Arbeitslosengeld. Eine Altersversorgung musste aus dem Ersparten oder durch die Sorge der Familienmitglieder um die aus Altersgründen arbeitsunfähigen Arbeiterinnen und Arbeiter erfolgen. ${ }^{64}$

63 Davis, James John. The Iron Puddler: My Life in the Rolling Mills and What Came of It. New York: Grosset \& Dunlap, 1922, S. 107. Davis wurde später Gewerkschafter und Kongressabgeordneter. Von 1921 bis 1930 bekleidete er das Amt des Arbeitsministers in den Kabinetten der Präsidenten Warren G. Harding, Calvin Coolidge und Herbert Hoover.

64 Davis, James John. The Iron Puddler, S.117. 
Ein gewisser Schutz lag in der Wahrung der Berufsgeheimnisse ungelernten Arbeitern gegenüber. Das Wissen um die fachgerechte Behandlung des Roheisens wurde nur von Generation zu Generation weitergegeben. Davis beendete seine Arbeit am Hochofen mit 18 Jahren, weil sein Vater sich noch nicht zurückziehen und seinen Platz dem Sohn überlassen wollte. ${ }^{65}$ Puddler waren geradezu die Aristokraten unter den Arbeitern, denn sie kontrollierten das Arbeitstempo aller Beschäftigten, bestimmten, wie gearbeitet wurde und hatten ein Mitspracherecht bei der Entlohnung ihrer Kollegen. Sie stellten ihre eigenen Helfer ein, die sie anlernten. $^{66}$

Damit stellten sie eine Herausforderung für die Fabrikbesitzer dar, denen viel daran lag, die noch verbliebene Arbeitsautonomie der Facharbeiter zu beenden. Zu diesem Zweck setzten sie immer mehr Maschinerie ein, mithilfe derer es möglich wurde, komplexe Arbeitsabläufe in ihre Fragmente zu zerlegen und so Facharbeiter durch ungelernte Arbeiter zu ersetzen, die geringere Stücklöhne erhielten. Im Zuge dieser Entwicklung ersetzte die Bessemerbirne den Puddelofen: 1872 waren lediglich vier Prozent des Schmelzeisens durch Einsatz des Bessemerprozesses in Stahl verwandelt worden. 1880 war dieser Prozentsatz auf 28 Prozent gestiegen. 1882 gab es bereits 15 große Stahlwerke mit insgesamt 37 Konvertern in den USA, die Stahl mittels des Bessemerverfahrens herstellten. Ihre Kapazität belief sich auf zwei Millionen Tonnen Stahl im Jahr. ${ }^{67} 1892$ entstammten schon mehr als 50 Prozent des erzeugten Stahls der Bessemerbirne. ${ }^{68}$ Die Arbeit an der Bessemerbirne erforderte zwar auch gut ausgebildete Spezialisten, doch konnte keine dieser Gruppen die absolute Kontrolle über den Produktionsprozess ausüben. ${ }^{69}$

Die Textilfabrik liefert das klassische Beispiel für den Aufstieg der mechanisierten Arbeit im 19. Jahrhundert. Mary, eine Weberin in der Fabrik in Fall River, Massachusetts, erzählte 1903 ihre Geschichte dem Independent. Sie arbeitete schon in der Fabrik seit sie zwölf Jahre alt war und hatte als 14-jährige als Weberin angefangen. Die Mechanisierung der Arbeit hatte bedeutet, dass sie als ausgebildete Weberin nur noch auf das Zerreißen des Fadens lauerte, also die ganze Zeit die Webmaschine überwachte. Die Arbeitsbedingungen waren unmenschlich. Der

65 Montgomery, The Fall of the House of Labor, S. 15.

66 Montgomery, The Fall of the House of Labor, S. $15 \mathrm{f}$.

67 Fitch, Thomas W. Bessemer Steel: Ores and Methods. St. Louis, MO: M. Renshaw, 1882, S. 25. Parallel zum Bessemerverfahren wurden auch gasbetriebene Siemensöfen, die den Stahl vorheizten, eingesetzt.

68 Montgomery, The Fall of the House of Labor, S. 27.

69 Montgomery, The Fall of the House of Labor, S. 29. 
Lärm war ohrenbetäubend und die Luft voller kleiner Partikel, die die Lunge reizten und zur Erkrankung der oberen Luftwege beitrugen. ${ }^{70}$

Weberinnen wie Mary wurden zunehmend nach Stücklohn bezahlt und nicht nach Stundenlohn. Sie arbeitete in der Regel zwölf Stunden am Tag und sechs Tage die Woche und kam so auf einen Tageslohn von einem Dollar am Tag. Um die Produktivität und die Ausbeutung zu steigern, mussten die Arbeiterinnen mehrere Webstühle gleichzeitig überwachen. ${ }^{71}$ Die überwiegende Mehrzahl der Beschäftigten waren junge, unverheiratete Frauen. Ein Aufstieg innerhalb der Hierarchie des Betriebs oder ein höherer Lohn waren wegen der vergeschlechtlichten Struktur dieser Arbeit unmöglich. Hinzu kamen sexuelle Übergriffe der männlichen Vorgesetzten. ${ }^{72}$

Während der 1880er Jahre verdoppelte sich die Zahl der im Ausland geborenen Fabrikarbeiterinnen. In der Fabrik in Amoskeag, NJ, bestand die Belegschaft mehrheitlich aus Einwandererinnen, davon viele aus den franko-kanadischen Gebieten. Ethnische Differenzen wie etwa zwischen aus England und aus Schottland eingewanderten Arbeiterinnen wie Mary einerseits und den Neuankömmlingen machten es schwer, diese Menschen zu gemeinsamem Handeln zu bringen. ${ }^{73}$ Der Charakter dieser Arbeit als Saisonarbeit war mit dafür verantwortlich, dass die Löhne niedrig waren. Die Existenz einer rudimentären Krankenversicherung - meist von der Gewerkschaft organisiert - war die Ausnahme. ${ }^{74}$ Nach 20 Jahren Schufterei in der Textilfabrik konnte sich Marys Familie noch nicht mal ein eigenes Haus leisten. Sie hatten gespart, aber es war immer etwas dazwischengekommen.

Im „Neuen Süden“ siedelten sich nun vermehrt auch Textilfabriken an, vor allem in den Carolinas und in Georgia. Hier arbeitete typischerweise die gesamte Familie in der Fabrik. Für African Americans blieben die Werkstore geschlossen, denn die Unternehmer stellten nur weiße Familien an. Lediglich die schmutzigsten, gefährlichsten und am schlechtesten bezahlten Stellen wurden afroamerikanischen Männern angeboten. Da im Süden die Löhne niedriger waren,

70 Adam, Hugo G. The Independent Journal. New York: Independent Journal Publishing Co, Band 58: 1905, S. 242.

71 Reef, Catherine. Working in America. New York: Facts on File, 2007, S. 138.

72 Blewett, Mary H. The Last Generation: Work and Life in the Textile Mills of Lowell, Massachusetts, 1910 -1960. Amherst, MA: University of Massachusetts Press, 1990.

73 Stein, Leon und Taft, Philis. Workers Speak: Self-Portraits. New York: Arno, 1971, S. 30. Montgomery, David. Workers'Control in America: Studies in the History of Work, Technology, and Labor Struggles. Cambridge, New York: Cambridge University Press, 1979, S. 37.

74 Adam, Hugo G. The Independent Journal. New York: Independent Journal Publishing Co, 1905, Band 58: S. 242. 
verlegten zahlreiche Textilunternehmen aus Neuengland ihren Standort nach südlich der Mason-Dixon-Linie.

In der Bekleidungsindustrie verwandelten die Mechanisierung und Arbeitsteilung das einstmalig unabhängige Handwerk der Schneiderei in eine Fabriktätigkeit. Die Einführung der Nähmaschine mit Fußantrieb in den 1850er Jahren und der Einsatz mechanischer Stoffschneidemaschinen in den 1870er Jahren transformierte den Arbeitsprozess: Durch die weitgehende Standardisierung der Schnittmuster konnte zudem ein Teil der notwendigen Arbeiten in Heimarbeit geleistet werden. In den 1880er Jahren ging man dazu über, ganze Bündel von vorgeschnittenen Rohteilen an Subunternehmer zu geben, die sich gegenseitig unterboten und dann die Teile von Frauen und Mädchen zuhause zusammennähen ließen. Diese Arbeit konnte auch in kleinen, ungelüfteten Räumen, den Sweatshops, oder in der Fabrik des Subunternehmers innerhalb einer Mietskaserne gemacht werden, wo Frauen und Kinder zu minimalen Löhnen die Arbeit leisteten, die früher von einem ausgebildeten Schneider ausgeführt worden war. ${ }^{75}$

Sadie Frowne war eine 16 Jahre alte polnische Jüdin, die während des letzten Jahrzehnts des 19. Jahrhunderts in einem Sweatshop in Brooklyn arbeitete und Unterröcke herstellte. In einem sieben mal fünf Meter großen Raum standen 14 Nähmaschinen. Frowne arbeitete hier elf Stunden am Tag. ${ }^{76}$ Sie verdiente etwa 4,50 Dollar in der Woche, von denen sie sich zwei Dollar vom Munde absparte und zurücklegte. ${ }^{77}$

Sadie Frowne war in mehrerer Hinsicht typisch. Lohnarbeiterinnen gegen Ende des 19. Jahrhunderts waren in der Regel jung und unverheiratet. Der größte Teil dieser Frauen arbeitete in der Textilbranche. Kurz dahinter folgte die Arbeit in der Fabrik. Die durchschnittliche Arbeiterin des Jahres 1890 war 22 Jahre alt und hatte mit 15 Jahren angefangen, Geld zu verdienen. Sie arbeitete zwölf Stunden am Tag, sechs Tage die Woche und verdiente weniger als 6 Dollar in der Woche. Das entsprach einem Stundenlohn von knapp neun Cent. Diese jungen Frauen entwickelten sich zu einer eigenen Subkultur. Sie arbeiteten hart und suchten als Ausgleich erschwingliche Vergnügungen wie Tanzlokale, organisierten sich in Clubs oder besuchten Amüsierparks. In der Regel arbeiteten sie etwa acht bis

75 Hapke, Laura. Sweatshop: The History of an American Idea. New Brunswick, NJ: Rutgers University Press, 2004, S. 61f. Zum Thema des „Working Girl“ in der fiktionalen Literatur viz. Hapke, Laura. Tales of the Working Girl: Wage-Earning Women in American Literature, 1890 1925. New York, Toronto, New York: Twayne Publishers, 1992.

76 Cott, Nancy F. Root of Bitterness: Documents of the Social History of American Women. Boston, MA: Northeastern University Press, 1996, S. 431.

77 Stein und Taft, Workers Speak, S. 118. 
zehn Jahre, bevor sie heirateten. Sie wurden diskriminiert und ökonomisch wie sexuell ausgebeutet. ${ }^{78}$

Die Arbeit in Kohle- oder Erzminen stellte zusammen mit der Holzwirtschaft die Bereiche dar, die am gefährlichsten waren. Die Arbeit in den Minen kam einer Schreckenskammer gleich. Ross Moudy war ein Bergarbeiter aus Cripple Creek, Colorado. Zunächst arbeitete er in einer sogenannten Chlorination Mill, in der Gold dem Gestein mithilfe chemischer Prozesse entzogen wurde. ${ }^{79}$ Neun oder zehn Stunden am Tag bei einem Lohn von 1,50 bis 2 Dollar am Tag atmete er Schwefeldioxid- oder Chlordämpfe ein. Dabei war der ihn umgebende Staub so dicht, dass die Sicht kaum 60 Zentimeter betrug. ${ }^{80}$ Auf Anraten des Betriebsarztes, der ihn zum absoluten Stillschweigen gegenüber der Betriebsleitung verpflichtete, gab er die Arbeit in der Chlormine auf und nahm eine Stelle in einer anderen Goldmine in Cripple Creek an. Diese Goldmine war relativ sicher - gemessen an seinem vorherigen Job. ${ }^{81}$

Beim Besuch einer Gruppe von Aktionären in der Mine kam es zu einem Beinaheabsturz eines der Besucher. Der Mann war weiß wie eine Wand und erklärte Moudy „[...] that instead of being paid $\$ 3.00$ per day they ought to have all the gold they could take out." ${ }^{82}$

Minenarbeiter starben auch bei Explosionen, Flözbrüchen und Grubenbränden. Neue Technologien beseitigten zwar einige der Gefahrenpotentiale, fügten aber auch neue hinzu. Grubenmaschinen lösten schwere Unfälle aus und führten zu Todesfällen. Mit dem Einsatz von mechanischen Bohrern und Vorschlaghämmern stieg die Staubkonzentration in der Luft. Chronische Lungenerkrankungen und frühe Invalidität waren die Folge. In den Untertagegruben des Westens kamen jährlich durchschnittlich 3,3 Prozent der Kumpel bei Grubenunfällen zu Schaden und 1,25 Prozent erlagen im gleichen Zeitraum ihren schweren Verletzungen. Selbst wenn es ohne spektakuläre Unfälle abging, atmete der Rest der Belegschaft unter Tage Staub und Mineralien ein, die nach wenigen Jahren chronische Erkrankungen mit sich brachten. Nach einem Jahr unter Tage trat Moudy der Gewerkschaft, der 1893 gegründeten Western Federation of Miners (WFM), bei, „[...] because I saw it would help me to keep in work and for protection

78 Forman-Brunell, Miriam. Girlhood in America: An Encyclopedia. Santa Barbara, CA: ABCCLIO, 2001, 2 Bände, Band 1, S. 283. McMaster, Lindsey. Working Girls in the West: Representations of Wage-Earning Women. Vancouver: UBC Press, 2008, S. 72.

79 Die Chlorination Mill befand sich in Gillette, Colorado. Charles William Henderson, Mining in Colorado: a history of discovery, development and production, S. 12.

80 Stein und Taft, Workers Speak, S. 105.

81 Stein und Taft, Workers Speak, S. 105.

82 Stein und Taft, Workers Speak, S. 106. 
in case of accident or sickness." ${ }^{\text {"83 }}$ Die Gewerkschaft hatte eine Kranken- und Unfallkasse und beschäftigte Krankenschwestern, „[...] so if one is alone and sick he is sure to be taken care of. "84 Moudy erkannte zwar, dass es innerhalb der Gewerkschaft einige Radikale gab, aber er bestand darauf, dass die meisten Gewerkschaftsmitglieder ,[...] believe the change will come about gradually and not by revolution. “85

Moudys größte Sorge war es, an einer CO2-Vergiftung zu sterben. Dies konnte leicht passieren, weil die Schächte und Stollen schlecht belüftet waren. ${ }^{86}$ Die Arbeitsbedingungen in der Mine von Ross Moudy waren nicht einmal besonders schlecht. Ein Kohlekumpel aus den Appalachen, der seit dem zwölften Lebensjahr im Pütt gearbeitet hatte, hatte diesen Job 23 Jahre lang inne. ${ }^{87}$ In den 1890 s verdienten die Arbeiter etwa 33 Dollar im Monat, was kaum für Unterkunft und Lebensmittel ausreichte. Der Kohlekumpel bemerkte sarkastisch, dass die unter Tage eingesetzten Maultiere besser ernährt würden als die Menschen. ${ }^{88}$

Amerikanische Arbeiterinnen und Arbeiter lebten im späten 19. Jahrhundert nahe am Existenzminimum. Obwohl die Reallöhne zwischen 1873 und 1893 statistisch um 15 Prozent zulegten, traf das nicht für alle arbeitenden Menschen im gleichen Maße zu. African Americans und Frauen erhielten weiterhin Hungerlöhne. Auch neu Eingewanderte nahmen einen Platz unten auf der Lohnskala ein. Nach den Krisen von 1873 und 1893 wurden zudem viele der von den Gewerkschaften errungenen Verbesserungen wieder zunichtegemacht. Zwar lagen die Durchschnittslöhne der Amerikaner höher als die der Europäer, doch kennzeichnet die Vereinigten Staaten die große Differenz der Löhne je nach Geschlecht und Herkunft.

Gegen Ende des Jahrhunderts entstand auch eine neue Klasse von Arbeitern die zahllosen Bürokräfte, Verkaufsfachleute, Telefonistinnen, Sekretärinnen und Manager, die als „white collar workers“ bezeichnet werden - auf Deutsch: An-

83 Stein und Taft, Workers Speak, S. 106. Die WFM war eine „internationale“ Gewerkschaft, da sie Arbeiter in den USA und Kanada organisierte und zwar nach dem Prinzip der Industriegewerkschaft. Sie war 1903-1904 an den Colorado Labor Wars um Cripple Creek und 1905 an der Gründung der Industrial Workers of the World (IWW) beteiligt. Henderson, Thomas. The Western Federation of Miners: The Course of Western Radical Unionism, 1903-1907. MS-Thesis. Charlotteville, VA: University of Virginia, 1968.

84 The Independent Journal, Band 57, 1904, S. 381.

85 Stein und Taft, Workers Speak, S. 107.

86 Stein und Taft, Workers Speak, S. 107.

87 Katzman, David M. und Tuttle, William M. Plain Folk: The Life Stories of Undistinguished Americans. Urbana, IL: University of Illinois Press, 1982, S. 143.

88 Katzman, David M. und Tuttle, William M. Plain Folk, S. 147. 
gestellte. ${ }^{89}$ Die Konzentrationsprozesse der Produktion sorgten für einer „Managerrevolution“, die in der Verwaltung oder in den Vorstandsetagen der Großunternehmen beschäftigt und von einer wachsenden Gruppe von Hilfskräften ergänzt wurden, die ihnen Tätigkeiten abnahmen. Ein Teil dieser Manager kam aus der Gruppe der vom Abstieg bedrohten Facharbeiter und stieg zu Industriemeistern oder Abteilungsleitern auf. Die schlechter bezahlten Angestelltenstellen wurden zunehmend mit Frauen besetzt, die in den Warenhäusern Tätigkeiten im Verkauf oder als Büroarbeiterinnen ausfüllten.

„The middle class is becoming a salaried class, and is rapidly losing the economic and moral independence of former days“, schrieb die Zeitschrift Independent im Jahr 1903.90 Der Independent lag damit zwar richtig, begonnen hatte dieser Trend aber schon Jahrzehnte zuvor. Der Konzentrationsprozess des Kapitals hatte schon nach dem Bürgerkrieg eingesetzt und größere Zusammenschlüsse, Trusts und Oligopole benötigten Manager und Leitungskräfte, um ihr Geschäft zu rationalisieren und zu kontrollieren und auf diese Weise die „unsichtbare Hand“ des Marktes (Adam Smith) durch die durchaus sichtbare Hand der Manager zu ersetzen. ${ }^{91}$ Die Einführung der Aktiengesellschaft trennte das Management von der Gruppe der Kapitalbesitzer, denn selbst hochbezahlte CEOs waren wenig mehr als privilegierte Angestellte. Diese Klasse der Manager rekrutierte sich aus der Gruppe der gut ausgebildeten weißen Mittelschicht. Kleine Unternehmer, die nach dem Bürgerkrieg ihr eigenes Unternehmen gestartet hatten, fanden sich nun als Angestellte einer Großfirma wieder, die ihnen ein Gehalt und vielleicht eine Erfolgsprämie zahlte.

Die Rationalisierung der Arbeit und die sich immer weiter erhöhenden Produktivität amerikanischer Unternehmen wurden mithilfe akribisch ausgetüftelter Studien, die den Grad der Arbeitsteilung vorantrieben, befördert. Diese Scientific Management oder wissenschaftliche Betriebsführung genannte Bewegung wurde in wesentlichen Teilen von Frederick Winslow Taylor (1856-1915) begründet, hatte aber seine Entsprechungen auch in Deutschland und anderswo. ${ }^{92}$ Taylor

89 Balack, Ulf Frank. Die White-Collar-Gruppe in Philadelphia: Entwicklung, Struktur und Mobilität, 1900 - 1970. Hamburg: Universitätsverlag, 2001. Davis, Clark. Company Men: White-Collar Life and Corporate Cultures in Los Angeles, 1892-1941. Baltimore, MD: Johns Hopkins University Press, 2000. Linder, Marc. „Time and a Half's the American Way“: A History of the Exclusion of White-Collar Workers from Overtime Regulation, 1868-2004. Iowa City, IO: Fanpihua Press, 2004. Wallis, Eileen V. Earning Power: Women and Work in Los Angeles, 1880-1930. Reno, NE: University of Nevada Press, 2010.

90 Zitiert in Zunz, Olivier. Making America Corporate, 1870-1920. Chicago, IL: University of Chicago Press, 1990, S. 12.

91 Smith, Adam. Wealth of Nations. New York: Cosimo, 2007, S. 351.

92 Taylor, Frederick Winslow. The Principles of Scientific Management. 
und andere Manager arbeiteten daran, die Planung und die Durchführung von Arbeit weiter zu trennen, durch Zeitstudien den Ablauf der Arbeiten zu optimieren, das Lohnsystem zu differenzieren und dadurch weitere Anreize zu schaffen, genaue Zielvorgaben für die Produktion zu machen und auf der Ebene der Werkshalle besondere Meister einzustellen, die auf das jeweilige Produkt und die für seine Herstellung notwendigen Verrichtungen und Handgriffe spezialisiert waren (Funktionsmeistersystem). Letzter Punkt erwies sich in der Praxis aber als nicht zielführend und wurde deshalb von nur wenigen Unternehmen umgesetzt. Scientific Management war aber das Kind seiner Zeit, da es am besten in einer Umgebung funktionierte, in der handwerklich organisierte Massenproduktion vorherrschte. In dem Maße, wie zu einem späteren Zeitpunkt Maschinen den Arbeitstakt vorgeben konnten, musste auch der Taylorismus angepasst werden. Doch liegt diese Phase im 20. Jahrhundert und soll hier nicht vertieft werden. ${ }^{93} \mathrm{Ab}$ 1882 jedenfalls ließ Taylor groß angelegte Time Motion Studies durchführen, bei denen Männer in weißen Hemden jeden Griff, jede Bewegung und jedes Innehalten bei der Arbeit akribisch stoppten und in Listen eintrugen. Ergänzt wurde das Ganze zu einem späteren Zeitpunkt durch die Hochgeschwindigkeitsfotographie mithilfe des Zusammenschaltens verschiedener Kameras, entwickelt von Eadweard Muybridge (1830 - 1904). Dadurch wurden auch das fotografische Zerlegen und die Dokumentation von Bewegungsabläufen möglich. ${ }^{94}$

Daneben und mitunter in Konkurrenz zu Versuchen, die Produktion effektiver zu gestalten, entwickelte sich eine innerbetriebliche Bürokratie. Alleine um die gigantischen Eisenbahnnetze zu verwalten, brauchte es ausgeklügelte Methoden der Verwaltung. Die Kommunikation lief über teure, langsame und nicht immer geheim zu haltende Telegraphie. ${ }^{95}$ Zwar war das Telefon schon 1878 erfunden worden, doch war es ein weiter Weg bis zur Verbreitung dieser Technologie. Na-

93 Gründung des Reichsauschusses für Arbeitszeitermittlung (REFA) in Deutschland 1924.

94 Eadweard Muybridge. Animal Locomotion Plate 59: Running Man. 1887. Minneapolis Institute of Art. Clegg, Brian. The Man Who Stopped Time: The Illuminating Story of Eadweard Muybridge: Pioneer Photographer, Father of the Motion Picture, Murderer. Washington, DC: Joseph Henry Press, 2007. Russell, Catherine. Experimental Ethnography. Durham, NC: Duke University Press, 1999, S. 69.

95 Für den Geschäftsgebrauch wurde es deshalb üblich, Telegramme zu verschlüsseln. Dies war auch keine Garantie für die Geheimhaltung des Telegramms, da Codebücher im Handel zu erwerben waren. Wenzlhuemer, Roland. Connecting the Nineteenth-Century World: The Telegraph and Globalization. Cambridge, New York: Cambridge University Press, 2013, S. 247. Derartige Telegrammcodes wurden auch von Regierungen und offiziösen Stellen benutzt. Siehe Archives Nationales [Frankreich]. $\mathrm{F}^{90} 20890$ Compagnie Française des Câbles Télégraphiques. 
tionale Telefonnetze wurden erst ab den 1890er Jahren möglich. ${ }^{96}$ Dies machte eine Ebene mittleren Managements mit Entscheidungskompetenz erforderlich, die zwischen den Unternehmensspitzen und der Arbeiterschaft standen. Sie betrachteten Gewerkschaften mit Argwohn, da sie befürchteten, diese würden in ihre Funktion als Manager eingreifen. Der typische Bildungsstand dieser Männer war ein High School-Abschluss, ein Privileg, dass damals auf acht Prozent der Bevölkerung beschränkt war. Sie entstammten also der weißen Mittelklasse und verdienten, gemessen an der Arbeiterelite der Zeit, relativ gut: etwa 1.500 bis 4.000 Dollar im Jahr. Die Unternehmensspitzen verfügten demgegenüber in der Regel über einen Hochschulabschluss und verdienten zwischen 4.000 und 15.000 Dollar im Jahr. ${ }^{97}$ Im Vergleich dazu konnte eine Einkäuferin in einem Kaufhaus wie Macy's 25 Dollar in der Woche verdienen - im Jahr 1871 ein Spitzenwert. ${ }^{98}$

Nicht alle Manager stammten indessen aus der Mittelklasse. Einige hatten sich als Facharbeiter hochgedient. Man muss sich vor Augen halten, dass es in den USA im Vergleich zu Europa erst sehr spät Ingenieurschulen gab und daher gut ausgebildete Facharbeiter so lange die Funktion der Ingenieure im europäischen

96 Problematisch für die Ausbreitung eines nationalen Telefonservice war das Monopol, das Graham Bell für seine Erfindung des Telefons 1876 und 1877 erhalten hatte. Die American Telephone and and Telegraph Company verteidigte dieses Monopol gegen kleinere Telefongesellschaften. Kunden des einen Telefonnetzes konnten nicht mir Benutzerinnen eines anderen Systems verbunden werden. Um 1890 hatten AT\&T rund eine Million Telefonkunden in den USA. Etwa 700.000 Anschlüsse existierten bei anderen Gesellschaften. Anrufe zwischen New York und Chicago waren bereits in den 1890er Jahren möglich. Nach 1899 überholte AT\&T - nun mit dem Hauptsitz in New York - alle anderen Netze dramatisch. Ein Telefongespräch zwischen San Francisco und New York war dennoch vor 1915 noch nicht möglich. Chapuis, Robert J. und Joel, Amos E. 100 Years of Telephone Switching (1878-1978). Amsterdam, Washington, DC: IOS Press. Ohmsha, 2003, 2 Bände, Band 1, S. 104. Murphy, The Telephone, S. 80 -91.

97 Wharton wurde 1881 als erste erfolgreiche Wirtschaftsfakultät der USA an der University of Pennsylvania gegründet. 1898 folgten die Universitäten von Chicago und California. Dartmouth folgte 1900. Erfolgreiche Manager um 1900 hatten also nur selten einen Universitätsabschluss in Wirtschaftswissenschaften. Applegate, The Rise of Advertising, S. 165. 1900 lag der Durchschnitt der jährlich gezahlten Gehälter bei 1.018 Dollar. United States und Census Office. Population of the United States by States and Territories, Counties, and Minor Civil Divisions, as Returned at the Twelfth Census: 1900. Washington, DC: United States Census Printing Office, 1901, S. 300. Ein Angestellter bei der Eisenbahn verdiente im Jahr 19001.011 Dollar. United States, Historical Statistics, Band 1, Series D 779-793, S. 168. Das Spitzengehalt eines Eisenbahnmanagers im Jahre 1888 betrug 35.000 Dollar. Walker und Vatter, The Rise of Big Government, S. 6.

98 Benson, Susan Porter. Counter Cultures: Saleswomen, Managers, and Customers in American Department Stores, 1890 -1940. Urbana, IL: University of Illinois Press, 1986, S. 25. 
System übernehmen mussten, bis Ingenieurschulen begannen, Absolventen auf den Arbeitsmarkt zu schicken. ${ }^{99}$

Die schon angesprochene Lebensgeschichte von Captain William „Billy“ Jones (1839 - 1889) bietet ein Beispiel für solch einen Aufstieg vom Facharbeiter zum Manager. Jones, wie James J. Davis aus Wales stammend, hatte als Zehnjähriger angefangen, in einem Eisenwerk zu arbeiten. Während des Bürgerkriegs diente er als Hauptmann in der US-Armee und benutzte diesen Dienstgrad den Rest seines Lebens. Als Andrew Carnegie sein Stahlwerk am Stadtrand von Pittsburgh gründete, stellte er Jones als seinen Direktor ein. Die Zeitgenossen waren sich einig, dass Jones der beste Stahlkocher seiner Generation war. Er liebte seine Arbeit und forderte sich und seinen Männern viel ab. Sein Motto lautete „Good wages and good workmen“. Carnegie versuchte dauernd, die Löhne seiner Arbeiter zu senken, doch Jones setzte sich für sie ein. 1881 setzte er die alte gewerkschaftliche Forderung nach einem Achtstundentag um, indem er Carnegie davon überzeugte, dass ein kürzerer Arbeitstag den Ertrag erhöhen würde, weil weniger Arbeiter fehlten und die Wahrscheinlichkeit für Unfälle abnehmen würde. Jones selbst erhielt ein Spitzengehalt, 25.000 Dollar im Jahr und verdiente damit genauso viel wie der US-Präsident. Dies war 1881 eine sehr hohe Summe und unterstrich den Wert, den Jones für Carnegie hatte. Sein gutes Gehalt bezog Jones nicht sehr lange. Er kam 1889 bei der Explosion eines Hochofens ums Le-

\footnotetext{
99 Belanger, Dian Olson. Enabling American Innovation: Engineering and the National Science Foundation. West Lafayette, IN: Purdue University Press, 1998. Curtis, O. B. und Gergel, Patricia M. The History of the National Council of Examiners for Engineering and Surveying, 1920-2004. Clemson, SC: National Council of Examiners for Engineering and Surveying, 2004. Dennis, Bernard G. American Civil Engineering History: The Pioneering Years. Proceedings of the Fourth National Congress on Civil Engineering History and Heritage, November 2-6, 2002, Washington, DC Reston, VA: American Society of Civil Engineers, 2003. Grayson, Lawrence P. The Making of an Engineer: An Illustrated History of Engineering Education in the United States and Canada. New York: Wiley, 1993. Herrin, Dean A. America Transformed: Engineering and Technology in the Nineteenth Century. Reston, VA: American Society of Civil Engineers, 2002. Kynell-Hunt, Teresa. Writing in a Milieu of Utility: The Move to Technical Communication in American Engineering Programs, $1850-1950$. Norwood, NJ: Ablex Pub. Corp, 1996. Rogers, Jerry R. Civil Engineering History: Engineers Make History. Proceedings of the First National Symposium on Civil Engineering History. New York: American Society of Civil Engineers, 1996. Ders. Engineering History and Heritage Proceedings of the Second National Congress on Civil Engineering History and Heritage. Reston, VA: American Society of Civil Engineers, 1998. Ders. International Engineering History and Heritage: Improving Bridges to ASCE’s 150th Anniversary. Proceedings of the Third National Congress on Civil Engineering History and Heritage, October 10-13, 2001, Houston, Texas. Reston, VA: American Society of Civil Engineers, 2001.
} 
ben - genauso wie 35.000 andere Arbeiter, die jedes Jahr Arbeitsunfällen zum Opfer fielen. ${ }^{100}$

Immer mehr Bereiche der industriellen Fertigung erforderten umfangreiche Verwaltungs- und Bürotätigkeiten. Der Anteil der White Collar Workers vergrößerte sich damit rapide. Auch innerhalb des Büros wurde die Arbeit rationalisiert und technisiert. Die Addiermaschine, die mechanische Schreibmaschine und die Kassenregistriermaschine wurden ab den 1880er Jahren in allen Büros und Warenhäusern verwendet. ${ }^{101}$ Die Arbeit in der Aktenablage und Führung der Geschäftskorrespondenz boten Frauen die Möglichkeit, in einem Büro zu arbeiten. Frauen erhielten geringere Löhne als Männer und waren in der Regel für die Bürotätigkeit besser ausgebildet. Außerdem standen Männern in der Verwaltung andere Posten offen. Im Jahr 1900 arbeiteten erstmalig mehr Frauen als Stenotypistinnen oder Sekretärinnen als Männer. ${ }^{102}$

Sylvie Thygeson (1868 - 1975) war eine der jungen Frauen, die in den 1880ern begann als Sekretärin zu arbeiten. Sie war in Forreston im agrarischen Westen des Staates Illinois aufgewachsen. Ihre Familie legte Wert auf eine gute Ausbildung. Ihr Vater arbeitete als Rechtsanwalt und ihre Mutter war stolz darauf, dass ihre acht Kinder einen High School-Abschluss ablegten. Als Sylvie Thygesons Vater 1884 starb, begann sie zu arbeiten. Nach einer kurzen Zeit als Lehrerin an einer Grundschule, lernte sie Stenographie und mit der Maschine zu schreiben und fand so Arbeit. ${ }^{103}$ Nachdem sie geheiratet hatte, gab sie ihre Berufstätigkeit auf. 104

Thygesons Geschichte unterstreicht die wachsende Bedeutung von Bürotätigkeiten für Frauen, vor allem aus der weißen Mittelklasse. Diese Frauen wurden anfangs wirklich wie die Maschinen, die sie bedienten, typewriters genannt und wurden damit virtuell eins mit der Schreibmaschine. Diesen enthumanisierenden Aspekt der Arbeit übersahen die meisten Frauen, da sie stolz auf ihre Arbeit und auf die relativ hohen Löhne waren, die sie mit nach Hause brachten. Um 1890 war

100 Eggert, Gerald G. Steelmasters and Labor Reform, 1886-1923. Pittsburgh, PA: University of Pittsburgh Press, 1981, S. 5-13, S. 21. Carnegie, The Autobiography of Andrew Carnegie, S. $203 \mathrm{f}$. 101 Strom, Sharon Hartman. Beyond the Typewriter: Gender, Class, and the Origins of Modern American Office Work, 1900 - 1930. Urbana, IL: University of Illinois Press, 1992.

102 Strom, Sharon Hartman. Beyond the Typewriter, S. 49, Table 2.

103 Suffragists Oral History Project. The Suffragists: From Tea-Parties to Prison: Oral History Transcript / and Related Material, 1972-1975. [Web Page]: http://www.mocavo.com/The-Suffra gists-From-Tea-Parties-to-Prison-Oral-History-Transcript-and-Related-Material-1972-1975/861022/ 87. Gesehen am 19.02.2015, S. 14.

104 Thygeson wurde später eine feministische Aktivistin, die sich vor allem für das Recht auf Geburtenkontrolle einsetzte. Hajo, Cathy Moran. Birth Control on Main Street: Organizing Clinics in the United States, 1916-1939. Urbana, IL: University of Illinois Press, 2010, S. 25 
bei den Berufswünschen junger weißer Frauen die Tätigkeit der Sekretärin ganz weit oben auf der Liste. Diese Arbeit galt nicht nur als hochwertiger als die Fabrikarbeit, sie brachte auch höhere Löhne bei kürzeren Arbeitszeiten mit sich. Bostons Büroarbeiterinnen verdienten mehr als sechs Dollar in der Woche, während Fabrikarbeiterinnen kaum auf einen Wochenlohn von fünf Dollar kamen.

Das Kaufhaus stellte eine weitere Gelegenheit für Frauen dar, eine Stelle außerhalb der Fabrikhalle zu finden. Die Konsumptionskultur des Industriekapitalismus, der ein großes Angebot an Gebrauchsgütern bereitstellte, dominierte zunehmend den amerikanischen Alltag - zumindest in den großen Städten. Das materielle Wohlergehen, das sich im Konsum Ausdruck verschaffte, wurde immer stärker das Ziel eines großen Teils der Bürgerinnen und Bürger. Erwerb und Konsum standen im Mittelpunkt und das Kaufhaus wurde zum steinernen Symbol dieses Strebens nach Konsum.

Das Kaufhaus war im 19. Jahrhundert innerhalb der neuen urbanen Kultur entstanden. Einkaufen wurde zu einer neuen Freizeitbeschäftigung, die in speziellen glamourösen und besonders ausgestalteten Umgebungen stattfand. Der Kauf auch relativ unbedeutender Gebrauchsartikel wie Bettzeug oder Männeroberbekleidung konnte so einen magischen Aspekt bekommen. Das Kaufhaus war architektonisch zwischen Kirche und Palast angesiedelt. Es wies aufwendig ausgestaltete Fassaden auf; hohe Räume, Lichter und Glasvitrinen, Marmor und Messing bestimmten das Design. Kaufhäuser wie Macy’s in New York, Wanamaker's in Philadelphia, Filene's in Boston und Marshall Field in Chicago versprachen die unmittelbare Befriedigung von materiellen Bedürfnissen. ${ }^{105}$

Ein solches Kaufhaus wies eine große Belegschaft auf, die man eher mit einem Hotel als mit einer Verwaltung vergleichen könnte: Lagerarbeiter, Kassiererinnen, Verkaufspersonal, Fahrstuhlführer, Buchhalter, Stenografinnen, Telefonistinnen, alle diese neuen Berufsgruppen signalisierten den allmählichen Übergang von einer rein auf Produktion ausgerichteten Wirtschaft zur Entwicklung des dritten Sektors: Dienstleistungen. In den späten 1890er Jahren hatte

105 Berkley, George E. The Filenes. Boston, MA: International Pocket Library, 1998. Lancaster, William. The Department Store: A Social History. London, New York: Leicester University Press, 1995. Leannah, Michael. Something for Everyone: Memories of Lauerman Brothers Department Store. Madison, WI: Wisconsin Historical Society Press, 2013. Santink, Joy L. Timothy Eaton and the Rise of His Department Store. Toronto, Buffalo, NY: University of Toronto Press, 1990. Soucek, Gayle. Marshall Field's: The Store That Helped Build Chicago. Charleston, SC: History Press, 2010. Whitaker, Jan. Service and Style: How the American Department Store Fashioned the Middle Class. New York: St. Martin's Press, 2006. 
Macy’s mehr als 3.000 Angestellte und Marshall Field beschäftigte sogar 6.000 Mitarbeiterinnen und Mitarbeiter. ${ }^{106}$

Unter der Belegschaft gab es sehr unterschiedliche Tätigkeiten, die auch unterschiedlich gut entlohnt wurden. Kassiererinnen und Verpackerinnen verdienten nur drei Dollar in der Woche, während Einkäuferinnen wie die schon erwähnte Belle Cushman schon 187125 Dollar in der Woche verdienten. ${ }^{107}$ Der strukturelle Sexismus funktionierte aber sehr gut. Cushman war eine Ausnahme. Frauen verdienten auch im Kaufhaus deutlich weniger als gleichqualifizierte Männer. Männliche Abteilungsleiter, sogenannte floorwalkers, verdienten zwischen zehn und 16 Dollar in der Woche. Eine Verkäuferin bei Macy's brachte es auf sechs Dollar. In allen Kaufhäusern herrschte eiserne Disziplin: Es war verboten, zu sitzen, es war untersagt, mit anderen Verkäuferinnen zu sprechen. Vergehen gegen die Disziplin wurden mit sofortiger Entlassung geahndet. Der arrogante Marshall Field (1834-1906) entließ außerdem jeden Beschäftigten mit Verbindung zur Gewerkschaft. ${ }^{108}$ Für angebliche Bummelei oder Kaugummikauen am Arbeitsplatz hagelte es Geldstrafen, die von den ohnehin mageren Löhnen abgezogen wurden.

Der Aufstieg des Industriekapitalismus veränderte nicht nur den Charakter der Arbeit und des Arbeitsplatzes, sondern griff auch nachhaltig in die Struktur des Familien- und Privatlebens ein. Privatleben und Arbeit wurden noch stärker voneinander getrennt, als dies früher der Fall war. In der vorindustriellen amerikanischen Gesellschaft hatte der Arbeitsplatz innerhalb des Hauses gelegen, in dem die Familie wohnte, oder war doch nicht weit entfernt vom Wohnort der Arbeiterinnen und Arbeiter gewesen. Die Industrialisierung zerstörte den Nexus von Arbeit und Privatleben und ersetzte ihn durch neue Formen der Freizeit. Verheiratete weiße Frauen blieben zuhause, wo sie oft unbezahlte Hausarbeit oder Heimarbeit verrichteten, Männer und unverheiratete Frauen arbeiteten in der Stadt. In besser gestellten Mittelklassefamilien erledigte das angestellte Personal Arbeiten wie Putzen, Kochen oder die Kindererziehung. Die Trennung von Wohnung und Arbeitsplatz erlaubte die Entstehung eines neuen Diskurses der

106 Benson, Counter Cultures, S. 23-25. Grippo, Robert M. Macy's: The Store, the Star, the Story. Garden City Park, NY: Square One Publishers, 2009. Hower, Ralph M. History of Macy's of New York, 1858-1919: Chapters in the Evolution of the Department Store. Cambridge, MA: Harvard University Press, 1943.

107 Benson, Counter Cultures, S. 25.

108 Miller, Donald L. City of the Century: The Epic of Chicago and the Making of America. New York: Simon \& Schuster, 1996, S. 258. 
Häuslichkeit, der das Heim und die Rolle von weißen Frauen innerhalb dieses Heims romantisierte. ${ }^{109}$

Die Trennung von Heim und Arbeit erlaubte es, das Heim als „haven in the heartless world“ zu konstruieren, das von der Ehefrau und Mutter geleitet wurde. Der Haushalt wurde eine „separate sphere“, ein Zufluchtsort für von der Arbeit zunehmend gestresste Mittelschichtsmänner. ${ }^{110}$ Dieser Kult der Häuslichkeit war nichts grundlegend Neues, da er schon in den 1820er Jahren angestoßen worden war, doch erfuhr er unter dem Eindruck der zunehmenden Entfremdung des Privaten und der Arbeitswelt neue Nahrung und konnte sich so noch bis zum Ende des 19. Jahrhunderts und darüber hinaus halten. ${ }^{111}$ Freilich wurde der Diskurs um die getrennten Sphären auch dadurch in Frage gestellt, dass immer mehr Frauen der Arbeitswelt zuströmten. Dies wurde von einigen Beobachterinnen als Krisenphänomen wahrgenommen, so als ob die sorgsam gehütete und gegen alle modernen Bedrohungen beschützte Geschlechterideologie des viktorianischen Zeitalters auseinander zu brechen drohte. Der „Engel im Haus“ drohte davonzuschweben. ${ }^{112}$

Grundsätzlich gilt festzuhalten, dass der Diskurs der Häuslichkeit vor allem in seiner frühviktorianischen Form sich vor allem mit der Rollenzuweisung der weißen Mittelklasse beschäftigte. „Wahre Frauen“ - im Gegensatz zu Frauen aus

109 Sawaya, Francesca. Modern Women, Modern Work: Domesticity, Professionalism, and American Writing, 1890 - 1950. Philadelphia, PA: University of Pennsylvania Press, 2004, S. 4- 17. Griswold, Robert L. Family and Divorce in California, 1850 - 1890: Victorian Illusions and Everyday Realities. Albany, NY: State University of New York Press, 1982, S. 175f. Coontz, Stephanie, Parson, Maya und Raley, Gabrielle. American Families: A Multicultural Reader. New York: Routledge, 2008, S. 103-114.

110 Lasch, Christopher. Haven in a Heartless World: The Family Besieged. New York: Basic Books, 1977. Matthews, Glenna. „Just a Housewife“: The Rise and Fall of Domesticity in America. New York: Oxford University Press, 1987. Hoganson, Kristin L. Consumers’ Imperium: The Global Production of American Domesticity, 1865-1920. Chapel Hill, NC: University of North Carolina Press, 2007. McHugh, Kathleen Anne. American Domesticity: From How-To Manual to Hollywood Melodrama. New York: Oxford University Press, 1999.

111 Broder, Sherri. Ideologies of Domesticity: 1890 - 1929. Dissertation, Amherst, MA: Hampshire College, 1979. Rauchway, Eric. The Refuge of Affections: Family and American Reform Politics, 1900 - 1920. New York: Columbia University Press, 2001, S.12. Robert M. Jackson spricht von einer Trennung der zwei Sphären, die um 1890 abgeschlossen gewesen sei. Die neuere Forschung sieht hier weniger einen Automatismus, sondern betont den Klassencharakter des Diskurses. Jackson, Robert Max. Destined for Equality: The Inevitable Rise of Women's Status. Cambridge, MA: Harvard University Press, 1998, S. 7 f.

112 „The Angel in the House“ war der Titel eines populären Gedichts von Coventry Patmore (1823-1896), das in drei Teilen zwischen 1854 und 1856 publiziert worden war. Robertson, Angelique. Women Who Did: Stories by Men and Women, 1890 -1914. London: Penguin, 2005. 
der Arbeiterklasse oder women of color - sollten ihre Aktivitäten auf das Haus beschränken. Die Distinktion zwischen der Lady und der Arbeiterin wurde damit gegen Ende des 19. Jahrhunderts prononcierter. Eine Lady residierte nun einmal im Heim. Arbeiterinnen hatten schnell ein soziales Stigma, denn sie konnten unmöglich Ladies sein. Im amerikanischen Slang wurden Prostituierte oft als working girls denunziert. Der Weg von der Arbeiterin zur Sexarbeiterin war nicht weit. Frauen der Arbeiterklasse wehrten sich gegen diesen impliziten Vorwurf. ${ }^{113}$

Das Aufeinandertreffen des Diskurses der Häuslichkeit und die ökonomischen Möglichkeiten der neuen funktionalen Mittelklasse in Zusammenhang mit der „neuen Immigration“ führten zu einer veränderten Bedeutung der Hausarbeit. Zunehmend nahmen Dienstmädchen und Haushaltshilfen der Lady auch Teile der Hausarbeit ab - jedenfalls im Norden der USA. Im Süden verließ man sich traditioneller Weise auf die Hilfe von afroamerikanischen Frauen im Haushalt. Hausarbeit im Norden wurde zunächst von sogenannten hired girls ausgeführt, die mit der Hausfrau gemeinsam Aufgaben im Haushalt erledigten. Später wurde aus diesen Frauen eine servant oder domestic, die in der Regel im Haushalt untergebracht war. Auch im Sprachgebrauch drückt sich die Tendenz einer größeren Klassendistinktion aus. Die urbane Mittelschicht verließ sich immer stärker auf die Arbeit von Haushaltsgehilfen. Sie „halfen“ nicht mehr im Haushalt, sondern erledigten alle Arbeiten, während die Dame des Hauses nur noch als Konsumptionsmanagerin in Erscheinung trat. Auch hier also war der Trend zu größerer Arbeitsteilung deutlich erkennbar. Schon 1870 hatten zwischen 15 und 30 Prozent aller Haushalte Bedienstete, die mit im Haus wohnten. 90 Prozent davon waren Frauen. ${ }^{114}$ Fast 1,3 Millionen Frauen waren 1900 als Dienstmädchen oder Haushaltsgehilfe in den USA tätig. Gegenüber 1890 stellte das eine fünfprozentige Steigerung dar. ${ }^{115}$

Das Leben als Dienstmädchen war hart. Diese Tätigkeit wurde zunehmend von eingewanderten Kräften aus Deutschland und Irland ausgeübt. Nach 1880 nahm der Anteil der new immigrants deutlich zu. Hausangestellte arbeiteten nicht

113 Pascoe, Peggy. Relations of Rescue: The Search for Female Moral Authority in the American West, 1874-1939. New York: Oxford University Press, 1990, S. 59. Meyerowitz, Joanne J. Women Adrift: Independent Wage Earners in Chicago, 1880-1930. Chicago, IL: University of Chicago Press, 1988, S. $30-45$.

114 Husband, Julie und O'Loughlin, Jim. Daily Life in the Industrial United States, 1870-1900. Westport, CT: Greenwood Press, 2004, S. 116. Dudden, Faye E. Serving Women: Household Service in Nineteenth-Century America. Middletown, CT, Scranton, PA: Wesleyan University Press. Distributed by Harper \& Row, 1983, S. 1.

115 United States. Bureau of the Census. Statistics of Women at Work. Washington, DC: Government Printing Office, 1907, S. 53 f. 
nur länger als andere Frauen, sie waren darüber hinaus auch während ihrer Freizeit auf Abruf, konnten das Haus also nur verlassen, wenn dies im Auftrag ihrer Arbeitgeber geschah. ${ }^{116}$ Haushaltsangestellte beklagten ihre fehlende Privatsphäre und die beschränkten Möglichkeiten, außerhalb des Haushalts Freizeit zu verbringen. Das Sozialprestige dieser Arbeit war zudem im Vergleich zu einer Tätigkeit im Verkauf sehr niedrig. ${ }^{117}$

Kein Wunder, dass eine Tätigkeit als Dienstmädchen oder Haushaltsgehilfin als die am wenigsten erstrebenswerten Arbeiten galten. Bei den neuen Möglichkeiten, die sich arbeitsuchenden Frauen in der Fabrik und im Büro öffneten, blieb die Hausarbeit für diejenigen übrig, die am geringsten qualifiziert waren. ${ }^{118}$

Bei der geringen Attraktivität des Berufsfelds und unter den sich verändernden Bedingungen für weibliche Berufstätigkeit kam es zu einer relativen Knappheit an Dienstpersonal. Frauen der Mittelklasse befeuerten einen Diskurs, der den Titel servant problem trug und davon handelte, wie schwer es sei, ,gute Hilfskräfte“ zu finden. Für Angehörige der Mittelklasse waren Hausangestellte ein Glücksfall, befreiten sie doch ihre Arbeitgeberinnen von den vielen Routinetätigkeiten im Haushalt. Hausangestellte machten es möglich, mehr Zeit mit den Kindern zu verbringen oder einer ehrenamtlichen oder sozialen Tätigkeit nachzugehen. Die Tätigkeit als Hausgehilfin verstärkte so paradoxerweise einerseits die Tendenz zur Häuslichkeit, andererseits ermöglichte sie für die Frauen, dies es sich leisten konnten, eine Köchin, ein Kindermädchen oder eine Zugehfrau einzustellen, eine Tätigkeit außerhalb des Haushalts, die den Diskurs der Häuslichkeit schwächte.

Mit der veränderten Bedeutung des Heims im Zusammenhang mit der neuen Häuslichkeit veränderte sich die Innenarchitektur des bürgerlichen Hauses in den Jahrzehnten nach dem Bürgerkrieg. Das Innere der Häuser wurde durch voluminösere Möbel und Nippes „kleiner“, der verfügbare Raum wurde zugestellt. Diese Innenarchitektur war ein Distinktionsmerkmal in Abgrenzung von den Wohnungen der Arbeiterklasse. Der Anteil des Hauseigentums im Vergleich zu Mietverhältnissen nahm dabei während des gesamten späten 19. Jahrhunderts zu: 46,5 Prozent aller Wohnungen wurden 1900 von ihren Bewohnern als Eigentum

116 Linton, Eliza Lynne. On the Side of the Maids. Cornhill Magazine, 29 (1874): 298 - 307, S. 299. 117 Quoted in Dickinson, Joan Younger. The Role of the Immigrant Women in the U.S. Labor Force, 1890 -1910. New York: Arno Press, 1980, S. 113.

118 Katzman, David M. Seven Days a Week: Women and Domestic Service in Industrializing America. New York: Oxford University Press, 1978, S. 3. 
besessen, 2000 waren 66,2 Prozent der Bevölkerung Besitzer eines Eigenheims oder einer Wohnung. ${ }^{119}$

Um 1890 hatte das typische Mittelklasseheim Zentralheizung, fließendes Warmwasser aus der Leitung und innerhalb der Wohnung befindliche Badezimmer. Elektrizität wurde Ende des 19. Jahrhunderts auch für Stadtbewohner erschwinglich. Die Einführung des elektrischen Lichts hatte tiefgreifende Auswirkungen auf das Sozialleben. Arbeit konnte auch nach Einbruch der Dunkelheit verrichtet und auch Hausarbeit musste nicht bei Tageslicht erledigt werden. ${ }^{120}$

Obwohl weniger weiße Mittelklassefrauen nach der Heirat arbeiteten, lag doch zwischen dem Familieneinkommen der Arbeiterklasse und dem der Mittelschicht eine riesige Kluft. Wohlhabende Mittelklassefamilien konnten nun die Produkte einkaufen, die von Frauen zuvor zuhause produziert worden waren. Die Hausarbeit der Mittelklassehausfrau wurde durch die Beschäftigung von Personal fast überflüssig. Der Diskurs der Häuslichkeit bedeutete im Unterschied zur frühviktorianischen Kultur vor dem Bürgerkrieg nun, dass weiße Mittelschichtsfrauen ungehindert ihren sozialen Verpflichtungen und karitativen Aufgaben nachgehen konnten. Man könnte überspitzt sagen, dass die Erringung des Frauenwahlrechts beispielsweise das Ergebnis der Freistellung weißer Reformerinnen von der Plackerei im Haushalt war.

Vergleichen wir zur Verdeutlichung dieser These zwei Haushalte miteinander: Margaret Byington (1877-1952), eine Sozialreformerin und Sozialarbeiterin, die eine bedeutende Untersuchung von Homestead, Andrew Carnegies Fabrikstadt vor den Toren von Pittsburgh, schrieb, berichtete über ihren Hausbesuch bei einer Arbeiterfamilie aus dem Osten Europas. ${ }^{121}$ Letztere lebte in einer Zweizimmerwohnung, die Teil einer Mietskaserne war. Die Mutter musste die Wäsche in einem Badezuber waschen, der auf einem Stuhl in der Mitte des Zimmers stand. Wäh-

119 United States und Bureau of the Census. Population Profile of the United States. Washington, DC: U.S. Dept. of Commerce, Bureau of the Census; 1999, S. 28-30. Die Werte für die elf Rebellenstaaten lagen dabei mit 40 Prozent deutlich unter dem Bundesdurchschnitt. United States, Department of Commerce und United States Census Bureau. Historical Census of Housing Tables. [Web Page]: https://www.census.gov/hhes/www/housing/census/historic/owner.html. Gesehen am 25.2.2015.

120 Rothman, Sheila M. Woman's Proper Place: A History of Changing Ideals and Practices, 1870 to the Present. New York: Basic Books, 1978, S. 15.

121 Byington, Margaret F. Homestead: The Households of a Mill Town. New York: Charities Publication Committee, 1910. Dies. What Social Workers Should Know about Their Own Communities: An Outline. New York: Charity Organization Department of the Russell Sage Foundation, 1912. 
rend der großen Wäsche musste sie sich um die beiden Kleinkinder kümmern und verhindern, dass sie sich am kochenden Waschwasser verbrühten. ${ }^{122}$

Wenn man diese Beschreibung mit der Darstellung eines Mittelklasseheims vergleicht, die aus dem Roman The Gilded Age von Mark Twain und Charles Dudley Warner stammt, fallen die Unterschiede ins Auge:

Every room had its book-cases or book-shelves, and was more or less a library; upon every table was liable to be a litter of new books, fresh periodicals and daily newspapers. There were plants in the sunny windows and some choice engravings on the walls, with bits of color in oil or watercolors; the piano was sure to be open and strewn with music; and there were photographs and little souvenirs here and there of foreign travels. ${ }^{123}$

In den Augen Byingtons und vieler ihrer Mittelschichtszeitgenossen konnte die Wohnung der osteuropäischen Einwandererfamilie kaum als „Heim“ beschrieben werden. Es gab nicht zur Kernfamilie gehörige Untermieter und zu wenig Betten; es fehlte an Privatheit und Platz.

\subsection{Das Auseinanderbrechen von Arbeit und Kapital, 1870-1894}

Fabrikstädte wie das von Byington untersuchte Homestead waren im 19. Jahrhundert ein alltäglicher Anblick geworden. Viele wurden eher zufällig gegründet, andere planvoll angelegt. 1892 lebten 8.000 Menschen in Homestead. Das ehemalige verträumte Dorf am Rande von Pittsburgh war nicht wiederzuerkennen. Die Stahlwerke vergrößerten sich ständig und drangen in Wohngebiete ein, so dass die Wohnbezirke der Arbeiterfamilien immer weiter in Richtung der angrenzenden Hügel und Täler verschoben wurden. In einem Viertel mit dem Namen Hollow fanden sich kleine Hütten, die wie Schwalbennester an die Hauswand geklebt lagen, ähnlich den Hütten in den brasilianischen Favelas. Diese zweizimmrigen Shanties beherbergten die Arbeiterfamilien der Stahlwerke von Homestead.

An anderen Orten, vor allem in New England, wurden die Industriestädte von langer Hand von den Unternehmen geplant und gebaut. Die Amoskeag Textilfabrik in Manchester, New Hampshire, war eine abgeschlossene Welt für sich, die nach einem Generalplan aus den 1830er Jahren entwickelt und 1837 vollendet

122 Byington, Homestead, S.145.

123 Twain, Mark und Warner, Charles Dudley. The Gilded Age: A Tale of To-Day. Hartford, CT: American Pub. Co; 1873, 21. Kapitel. [Web Page]: http://xroads.virginia.edu/ Hyper2/Gilded/ ch21.txt. Gesehen am 31.10.2008. 
worden war. ${ }^{124}$ Hinter derartigen Planungen stand ein wohlwollender Paternalismus der Unternehmen. ${ }^{125}$ Die Arbeiterfamilien wurden in diesem Diskurs zu Kindern degradiert. Migranten und Migrantinnen sollten in Wohnanlagen wieder von Amoskeag zu amerikanischen Staatsbürgern sozialisiert werden. Gleichzeitig sollten sie von radikalen Agitatoren, der Versuchung, einer Gewerkschaft beizutreten oder zu streiken, ferngehalten werden. ${ }^{126}$

In den 1880ern zählte Amoskeag Zehntausende von Werktätigen, von denen viele in dem Unternehmen gehörenden Mietskasernen lebten. Die Beschäftigten nannten diese Wohnungen „corporations.“ Es handelte sich bei ihnen um dreibis fünfstöckige Ziegelbauten, die sich entlang der Hauptverbindungsstraßen vom Stadtzentrum zu den Fabriktoren erstreckten. Die Miete kostete einen Dollar pro Monat. Um an eine der begehrten Wohnungen zu gelangen, musste mehr als ein Familienmitglied in der Textilfabrik arbeiteten, eine Bedingung, die die Aufrechterhaltung der Kinderarbeit förderte. Im Vergleich $\mathrm{zu}$ den Elendshütten in Homestead boten die Unternehmenshäuser in Amoskeag jedoch beachtliche Wohnqualität. Nur ein Drittel der Arbeiterfamilien konnte in derartigen Wohnungen unterkommen. Die Mehrzahl der Arbeitenden lebte in Mietswohnungen in der Stadt und etliche besaßen sogar eigene Häuser. Die Textilfabrik übte dennoch einen großen Einfluss auf das Alltagsleben aller Arbeiter aus. „If you told the boss to go to hell, you might as well move out of the city. The boss had the power to blackball you for the rest of your days“, berichtete ein Arbeiter. ${ }^{127}$

Die vielleicht berühmteste und berüchtigtste Unternehmensstadt der USA wurde vom Schlafwagenkönig George Mortimer Pullman (1831-1897) knapp 15 Kilometer südlich von Chicago am Ufer des Lake Calumet gebaut. Als Reaktion auf den großen Eisenbahnstreik von 1877 beschloss Pullman, mit seiner Fabrik ans Westufer des Sees umzuziehen, um seine Arbeiter dem „schlechten Einfluss“

124 Hareven, Tamara K. und Langenbach, Randolph. Amoskeag: Life and Work in an American Factory-City. Hanover, NH: University Press of New England, 1995.

125 Crawford, Margaret. Building the Workingman's Paradise: The Design of American Company Towns. London, New York: Verso, 1995, S. 12-34.

126 Die Bevölkerung von Homestead setzte sich vorwiegend aus Immigrantinnen und Immigranten der „zweiten Immigration“ zusammen. Ab 1920 - also außerhalb unseres Geschichtszeitraums - kamen viele African Americans hinzu. Classroom Teaching Resources, „Homestead Census“. [Web Page]: http://archives.dreamhosters.com/items/show/128. Gesehen am 11.9.2014. Typische Mill Towns in Neuengland waren Berlin, New Hampshire (gegründet 1829), berühmt für seine Papierindustrie, New Haven, Connecticut, das heute Sitz der ehrwürdigen Yale University ist, im 19. Jahrhundert aber das Zentrum der amerikanischen Waffenindustrie darstellte, und Gardner, Massachusetts, bedeutender Sitz der Möbelindustrie.

127 Witt, John Fabian. The Accidental Republic: Crippled Workingmen, Destitute Widows, and the Remaking of American Law. Cambridge, MA: Harvard University Press, 2004, S. 55. 
der Stadt Chicago zu entziehen. 1880 erwarb Pullman 4.300 Acres bis dato unbesiedelten Landes, auf denen er seine Modellstadt durch den Architekten und Anhänger der Christian Science Solon Spencer Beman (1853-1914) im Queen Anne-Stil errichten ließ. Die Stadt hatte einen Flair von Ordnung und Luxus, denn - so Pullman - „[It was...] to the employer's interest to see that his men are clean, contented, sober, educated, and happy. “128 Pullman glaubte fest daran, dass seine praktische Menschenliebe ihm größere Profite bescheren würde, da sie „[...] loss of time and money consequent upon intemperance, labor strikes, and dissatisfaction [...] “ verhindere. ${ }^{129}$

Beim Einzug der ersten Familie nach Pullman am 1. Januar 1881 wies die Stadt Parks, künstliche Gewässer, Brunnen, Spielplätze, einen Gemeindesaal, eine Bibliothek, ein Hotel, ein Verwaltungsgebäude, Geschäfte und Markthallen auf. 1.800 Wohnungen waren bezugsfertig. Es gab praktisch alles, außer einer Kneipe. Ein Arbeiter schrieb dem englischen Reformer William Thomas Stead (1849-1912), Autor von „If Christ Came to Chicago“, und analysierte die Position der Bewohner von Pullman folgendermaßen:

The residents in the city [...] ,paid rent to the Pullman Company, they bought the gas from the Pullman Company, they paid water-tax to the Pullman Company. Indeed, even when they bought gingham for their wives of sugar for their tables at the arcade or the markethouse, it seemed dealing with the Company. They sent their children to Pullman's school, attended Pullman's church, looked at but dared not to enter Pullman's hotel with its private bar, for that was the limit. ${ }^{\text {'130 }}$

Die einschüchternde Wirkung der Omnipräsenz von Pullman im Leben seiner Arbeiter war das wohl größte Manko in Pullmans Idee. In seinem Bestreben, eine anständige Umwelt zu kreieren, machte Pullman seine eigenen Vorstellungen und Wünsche zum Maßstab des Lebens seiner Mitarbeiter. Mit ihren sauberen und breiten Straßen, ihren Parks und Modellwohnungen war Pullman anderen Industriestädten um Längen voraus. Doch Pullman erwartete auch finanziellen

128 Miller, Donald L. City of the Century: The Epic of Chicago and the Making of America. New York: Simon \& Schuster, 1996, S. 236. Adams, Sean Patrick. An Uneasy Truce: Worker Responses to Pullman's Model Town, 1880-1894. Madison, WI: University of Wisconsin Press, 1992, S. 19. Buder, Stanley. Pullman: An Experiment in Industrial Order and Community Planning, 1880 1930. New York: Oxford University Press, 1967, S. 40.

129 Cutler, Irving. Chicago: Metropolis of the Mid-Continent. Carbondale, IL: Southern Illinois University Press, 2006, S. 132. [Anonymous]. The Story of Pullman. Chicago, IL: Blakely \& Rogers, 1892, S. $32 \mathrm{f}$.

130 Stead, William Thomas. If Christ Came to Chicago! A Plea for the Union of All Who Love in the Service of All Who Suffer. London: Pub. at the Office of "The Review of Reviews", 1894, S. 77. 
Gewinn. Er hoffte auf eine Gewinnrate von sechs Prozent im Jahr, weshalb die Mieten in seiner Stadt deutlich höher waren als anderswo. Der Kauf der Häuser war nicht vorgesehen. George Pullman weigerte sich ,[to...] sell an acre under any circumstances. “131 Er wollte die vollkommene Kontrolle über seine Stadt nicht hergeben, weil er so über das Instrument der Wohnungskündigung Störenfriede und Revoluzzer fernhalten wollte. ${ }^{132}$ Die erstaunten Besucher der Stadt übersahen schnell, dass der Ort für seine Bewohner so etwas wie einen goldenen Käfig darstellte. ${ }^{133}$

Als Gewerkschaftsmitglieder ein Treffen in Pullman organisieren wollten, wurden sie von Spitzeln der Geschäftsleitung überwacht. Der junge, 1879 in Heidelberg promovierte Wirtschaftswissenschaftler und Progressive Richard T. Ely (1854-1943) traf den Nagel auf den Kopf als er 1884 bemerkte:

In looking over all the facts of the case, the conclusion is unavoidable that the idea of Pullman is un-American. [...] It is benevolent, well-wishing feudalism, which desires the happiness of the people, but in such way as shall please the authorities. ${ }^{134}$

Auch in einigen Textilstädten des Südens wurde eine Art von kapitalistischem Paternalismus durchgesetzt. ${ }^{135}$

Diese weitgehend namen- und gesichtslosen Unternehmensstädte wiesen Geschäfte, Kirchen, Schulen und Häuser im Besitz des Unternehmens auf. Soziale Kontrolle wurde so auf allen Ebenen ausgeübt. Die Beschäftigten erhielten keinen Lohn, sondern „Scrip“, eine Art Privatwährung, die nur in den Geschäften des Unternehmens eingelöst werden konnte. Da jegliche Konkurrenz fehlte, lagen die Preise deutlich über dem Durchschnittsniveau, was zu Schulden führte, wodurch die Arbeiter - dem Crop-Lien-System des Südens nicht unähnlich - zum virtuellen Inventar des Unternehmens wurden. Gegen Ende des 19. Jahrhunderts lebten 92 Prozent der Textilarbeiterfamilien im Süden in solchen Unternehmensstäd-

131 Lindsey, Almont. The Pullman Strike: The Story of a Unique Experiment and of a Great Labor Upheaval. Chicago, IL: University of Chicago Press, 1964, S. 66.

132 Monti, Daniel J. Race, Redevelopment, and the New Company Town. Albany, NY: State University of New York Press, 1990, S. 12.

133 Buder, Pullman, S. 99.

134 Horn, Steven Edward. Property and Democracy: Authority in Four American Property-Rights Regimes. Ann Arbor, MI: Dissertation an der University of Southern California, Los Angeles, CA, 2008, S. 134. Lindsey, Almont. The Pullman Strike: The Story of a Unique Experiment and of a Great Labor Upheaval. Chicago, IL: University of Chicago Press, 1964, S. 86.

135 Garner, John S. The Company Town: Architecture and Society in the Early Industrial Age. New York: Oxford University Press, 1992, S. 144. 
ten. ${ }^{136}$ Derartige Städte gab es in allen Staaten südlich der Mason-Dixon-Line, jedoch bildeten die Staaten Georgia und South Carolina das Zentrum.

Diese Unternehmensstädte stellen das dramatischte Beispiel dafür dar, wie traditionelle Formen der Arbeit wie die Sklaverei die klassische Lohnarbeit überformten und veränderten. Der „doppelt freie Lohnarbeiter“ (Karl Marx) - frei von Produktionsmitteln und frei seine Arbeit wohlfeil zu verkaufen - war hier eine Illusion. Die interne Kolonisierung des Südens hatte eine Arbeitsorganisation mit sich gebracht, die in der Geschichte des Industriekapitalismus einzigartig war.

\subsection{Critical Juncture: Die Arbeiterbewegung im Spannungsfeld von Klassenkampf und Sozialpartnerschaft}

Die organisierte Arbeiterbewegung war keine Erfindung des Gilded Age. Seit der Kolonialzeit hatten sich Facharbeiter in Gewerkschaften zusammengeschlossen. 1866 hatte William H. Sylvis (1828-1869), ein Eisengießer aus Philadelphia, die National Labor Union gegründet, die alle Facharbeiter einschließen sollte. Sie bestand nur bis 1874, im Wesentlichen, weil die Gewerkschaft sich sehr stark in der Währungspolitik der Zeit engagierte und erfolglos versuchte, an Wahlen teilzunehmen. ${ }^{137}$ Hinzu kam, dass die Mechanisierung auch die Facharbeiter bedrohte, weil ihre Arbeit billiger und besser von angelernten Kräften unter Einsatz von Maschinen bewerkstelligt werden konnte. Viele der alten Facharbeitergewerkschaften der 1860er Jahre verschwanden so oder wurden von Managern und Unternehmern vehement bekämpft. Sicherlich trug zu den Problemen der Gewerkschaften auch bei, dass sie sich lokal - also auf Ebene des einzelnen Betriebs - organisierten, während die Produktion in zunehmenden Maße in verschiedenen vertikal oder horizontal integrierten Betrieben organisiert wurde. ${ }^{138}$

Im späten 19. Jahrhundert hatten auch die Facharbeiter weitgehend die Kontrolle über ihre Arbeitsprozesse verloren. Der einzelne Arbeiter sah sich der anonymen Maschinerie des Industriekapitalismus gegenüber. Arbeit verlor ihre humanistische Konnotation, die sie in der Produzentenethik (producerism) des

136 Green, Hardy. The Company Town: The Industrial Edens and Satanic Mills That Shaped the American Economy. New York: Basic Books, 2010, S. 97.

137 Einen biographischen Abriss des Lebens von Sylvis gibt Sylvis, James C. The Life, Speeches, Labors and Essays of William H. Sylvis: Late President of the Iron-Moulders' International Union; and also of the National Labor Union. Philadelphia, PA: Claxton, Remsen \& Haffelfinger, 1872, S. $1-94$.

138 Whitten, David O. und Whitten, Bessie E. The Birth of Big Business in the United States, 1860 - 1914: Commercial, Extractive, and Industrial Enterprise. Westport, CT: Praeger, 2006, S. 16. 
frühen 19. Jahrhunderts noch gehabt hatte. ${ }^{139}$ Es waren zuallererst die Abwehrkämpfe gegen diese Form der Nivellierung der Arbeit, die Arbeiter dazu bewegte, sich in größeren Verbänden zusammenzuschließen, wobei Gewerkschaften nur einen Teil dieser Verbände ausmachten. Reformbewegungen und alternative Parteien versuchten ebenfalls, sich dem Vordringen des Kapitalismus entgegenzustemmen.

Ein 23-jähriger Maschinenschlosser aus New York, der seinen Beruf seit neun Jahren ausübte, beschrieb 1883 vor einer Senatskommission, wie sich sein Arbeitsleben verändert hatte:

The trade has been subdivided and those subdivisions have been again subdivided, so that a man never learns the machinist's trade now. Ten years ago he learned, not the whole trade, but a fair portion of it. Also, there is more machinery used in the business, which again makes machinery. In the case of making the sewing machine, for instance, you find that the trade is so subdivided that a man is not considered a machinist at all. Hence it is merely laborers' work and it is laborers that work that branch of our trade. ${ }^{140}$

Der junge Maschinenschlosser hatte klar erkannt, welche Kräfte hier am Werk waren. Berufe, die eine Ausbildung voraussetzten, waren immer weiter mechanisiert worden. Qualifizierte Arbeit war durch unqualifizierte Arbeit ersetzt worden. Der Konkurrenzdruck brachte Unternehmer wie Andrew Carnegie dazu, die Kosten immer weiter zu senken - dies geschah meistens in der Form der Einführung neuer, arbeitssparender Maschinen. Löhne für Facharbeiter konnten auf diese Weise abgesenkt werden. Die alte Arbeiterschaft übte immer weniger Kontrolle über die Arbeitsabläufe aus.

Der Verlust der Unabhängigkeit kollidierte mit dem tiefsitzenden Glauben amerikanischer Arbeiter an den Individualismus. Abhängige Arbeit sollte nur eine Übergangstätigkeit bis zur Etablierung eines eigenen Geschäfts oder Betriebs sein. Der self-made man entstand als Trope in den 1840er Jahren, bewahrte aber seine

139 Finzsch, Konsolidierung und Dissens, S. 302-304. Ohrem, Dominik. „American Knights in Buckskin“: Das Männlichkeitsdispositiv der frontier und Narrative der Nationsbildung in den USA des 19. und frühen 20. Jahrhunderts. Kleinau, Elke, Schulz, Dirk und Völker, Susanne (Hg.). Gender in Bewegung: Aktuelle Spannungsfelder der Gender und Queer Studies. Bielefeld: transcript, 2013, S. 289-306, S. 295. Rosanne Currarino unterscheidet zwischen verschiedenen Formen des Producerism und macht deutlich, dass die „ältere“ Form des proprietary producerism der 1840er und 1850er Jahre nach 1873 durch eine neuere Form abgelöst wurde. Currarino, Rosanne. The Labor Question in America: Economic Democracy in the Gilded Age. Urbana, IL: University of Illinois Press, 2011, S. 12-16.

140 United States, Congress, Senate und Committee on Education and Labor. Report of the Committee of the Senate upon the Relations between Labor and Capital. Washington, DC: Government Printing Office, 1885, 4 Bände, Band 1, S. 755. 
diskursive Dominanz bis zum Ende des Jahrhunderts. ${ }^{141}$ Mit dem Aufstieg der Großindustrie wuchs der Kapitalbedarf, den man zur Gründung eines eigenen Betriebes benötigte, und damit wurde es für die meisten Amerikaner unmöglich, ein eigenes Unternehmen zu gründen. ${ }^{142}$

Derselbe Arbeiter drückte seine wachsende Desillusionierung vom amerikanischen Traum aus. Auf die Frage, ob seine Kollegen jemals erwarten könnten, selbst Unternehmer zu werden, sagte er: „[...] speaking generally, there is no chance. They have lost all desire to become bosses now. [...] the trade has become demoralized. First they earn so small wages; and, next, it takes so much capital to become a boss now that they cannot think of it, because it takes all they can earn to live. ${ }^{143}$

Die Ränge der Lohnarbeiter, die nach Stücklohn oder nach Stundenlohn bezahlt wurden, stiegen im gleichen Maße, wie die Zahl der Großbetriebe zunahm. 1870 bestand schon die Hälfte der amerikanischen Arbeiterklasse („gainfully employed“) aus Lohnarbeitern. Die Zahl der nicht im Agrarsektor arbeitenden Lohnarbeiter und Lohnarbeiterinnen stieg nach 1870 mehr als doppelt so

141 Zur diskursiven Durchschlagskraft der Trope für die Arbeiterschaft siehe Catano, James V. Ragged Dicks: Masculinity, Steel, and the Rhetoric of the Self-Made Man. Carbondale, IL: Southern Illinois University Press, 2001, S. 121-151. An Quellen erwähne ich hier nur eine kleine repräsentative Auswahl. Chubbuck, Emily. Allen Lucas, the Self-Made Man. New York: Lewis Colby \& Co, 1847. Judson, Emily C. Allen Lucas: The Self-Made Man. Utica, NY: Bennett, Backus, \& Hawley, 1844. Cleveland, Grover. The Self-Made Man in American Life. New York: T.Y. Crowell, 1897. Howard, Horatio P. A Self-Made Man, Capt. Paul Cuffee. [New York: 1913?]. McClelland, Margaret Grenaway. A Self-Made Man. Philadelphia, PA: Lippincott Company, 1887. Sibley, John Langdon und Morison, John Hopkins. A Remarkable Self-Made Man. Cambridge MA: J. Wilson and Sons, 1886. Anderson, William. Self-Made Men. London: J. Snow, 1865. [Anonymous]. The United States Biographical Dictionary and Portrait Gallery of Eminent and Self-Made Men. Chicago, IL, New York: American Biographical Publishing Company, 1875. Chamberlain, J. S. Success or, The Triumphs and Achievements of Self-Made Men. Chicago, IL: Merchants' Specialty Co, 1891. Craig, Adam. Room at the Top, or, How to Reach Success, Happiness, Fame and Fortune: With Biographical Notices of Successful, Self-Made Men, Who Have Risen from Obscurity to Fame... Also, Rules for Behavior in Society. Augusta, ME: True, 1884. Farningham, Marianne. New World Heroes: Lincoln and Garfield. The Life-Story of Two Self-Made Men, Whom the People Made Presidents. London: W. Scott, 1884. Seymour, Charles C. B. Self-Made Men. New York: Harper \& Bros, 1858. Stowe, Harriet Beecher, Stowe, Charles Edward und Munroe, Kirk. The Lives and Deeds of Our Self-Made Men. Boston, MA: Estes and Lauriat, 1889. Siehe auch die vergleichende Dissertation von Reick, Philipp. „Labor is Not a Commodity“: Contested Working Class Discourse and the Movement to Shorten the Workday in Berlin and New York City in the Late 1860s and Early 1870s. Berlin: Freie Universität, 2015.

142 United States; Congress; Senate; Committee on Education and Labor. Report of the Committee of the Senate upon the Relations between Labor and Capital, Band 1, S. 756.

143 United States; Congress; Senate; Committee on Education and Labor, S. $756 \mathrm{f}$. 
schnell wie die Gesamtbevölkerung. 1870 gab es 35,9 Prozent männliche Industriearbeiter, 1900 waren es 48,3 Prozent der Beschäftigten. ${ }^{144}$ Die Vereinigten Staaten, einst eine Gesellschaft kleiner Ladenbesitzer, Handwerker und Bauern, hatten sich in eine Nation von Aktiengesellschaften und Lohnarbeit verwandelt.

Für Facharbeiter, die Genugtuung und Stolz aus ihrer Arbeit schöpften, bedeutete der Verlust ihrer Facharbeiterposition vor allem den Verlust der Kontrolle über den Produktionsprozess. Aus dem Gefühl der Machtlosigkeit entstand der Drang zu kollektivem Widerstand. Alleine, so viel war klar, hatte der Facharbeiter keine Chance, sich den Tendenzen der Nivellierung zu widersetzen. Zusammen, so hofften Etliche, könne man die verloren gegangene Kontrolle zurückgewinnen. Der New Yorker Maschinenschlosser hatte auch hier keine Illusionen. Für ihn gab es nur eine Lösung: die Abschaffung des Privateigentums an Produktionsmitteln. ${ }^{145}$

Der große Eisenbahnstreik von 1877 belebte die Gründung von Gewerkschaftsorganisationen in den USA. Die Knights of Labor (KoL), die erste Massenorganisation der amerikanischen Arbeiterschaft, profitierte am meisten von der gestiegenen Bereitschaft der arbeitenden Menschen, sich zu organisieren. Der Noble and Holy Order of the Knights of Labor war 1869 von Uriah Smith Stephens (1821-1882), einem Stoffzuschneider aus Philadelphia gegründet worden. Smith war außerdem Freimaurer und einige der Sitten und Gebräuche der KoL stammten aus dem Umfeld der im 19. Jahrhundert allgegenwärtigen geheimen Bruderschaften. Wie die Freimaurer waren die KoL ein Geheimorden, allerdings hatten sie friedliche Ziele und imaginierten eine weltweite Bruderschaft aller Arbeitenden, vom einfachen Lohnarbeiter bis zum Handwerksmeister, vom Textilarbeiter in Massachusetts zum Stahlkocher in Georgia. ${ }^{146}$ Obwohl die KoL keine prominente Rolle im Eisenbahnstreik von 1877 gespielt hatten, erlebten sie in seinem Gefolge einen sagenhaften Zulauf von Mitgliedern. 1878 wurde die Verpflichtung zur Geheimhaltung abgeschafft. Gleichzeitig begann eine offensive Werbekam-

144 Montgomery, The Fall of the House of Labor, S. 49.

145 United States; Congress; Senate; Committee on Education and Labor. Report of the Committee of the Senate upon the Relations between Labor and Capital, Band 1, S. 760.

146 Weir, Robert E. Beyond Labor's Veil: The Culture of the Knights of Labor. University Park, PA: Pennsylvania State University Press, 1996, S. 22-25. Milano, Kenneth W. Hidden History of Kensington \& Fishtown. Charleston, SC: History Press, 2010, S. 63-66. Die klassische Studie zu den Knights of Labor ist immer noch Fink, Leon. Workingmen's Democracy: The Knights of Labor and American Politics. Urbana, IL: University of Illinois Press, 1983. Zur Arbeit der KoL im Süden siehe Hild, Matthew. Greenbackers, Knights of Labor, and Populists: Farmer-Labor Insurgency in the Late-Nineteenth-Century South. Athens,GA: University of Georgia Press, 2007. 
pagne für die Knights, die Arbeiter und Arbeiterinnen, gelernte und ungelernte, Immigrantinnen und Immigranten miteinschloss.

Unter ihrem Vorsitzenden, dem Grand Master Workman Terence Vincent Powderly, wurden die KoL zur wichtigsten Arbeiterorganisation der 1880er Jahre. ${ }^{147}$ Die Gewerkschaft wuchs innerhalb weniger Jahre von 1881 (wenige tausend Mitglieder) zu einer Mitgliederzahl von 700.000 Menschen. ${ }^{148}$ Die KoL forderten eine demokratische Organisation der Arbeiter und Arbeiterinnen in Kooperativen, freien Zugang zum Land, die Überführung der Eisenbahn in Staatseigentum, gleiche Bezahlung für Frauen, die Einführung einer Einkommenssteuer und die Abschaffung der Kinderarbeit. Klassengrenzen sollten abgeschafft werden, weshalb auch Unternehmer den KoL beitreten konnten - wenn auch „Parasiten“ wie Bankiers, Spekulanten, Spieler, Rechtsanwälte und Schnapshändler von den KoL ausgeschlossen blieben. ${ }^{149}$ „I hate the word ,class“ and would drive it from the English language if I could“, stellte Powderly fest. ${ }^{150}$ Gekoppelt wurde die „Klassenanalyse“ der Opposition von produktiven Menschen einschließlich Unternehmern und „Parasiten“, zu denen später noch die Immigranten und Immigrantinnen kommen sollten, mit einer ökonomischen Theorie, die weder die Kapitalakkumulation noch den Begriff des Mehrwerts kannte. ${ }^{151}$ Konsequenter-

147 Dieser Titel stammte noch aus dem Umfeld der Freimaurerbünde, die für die KoL Pate gestanden hatten. Phelan, Craig. Grand Master Workman: Terence Powderly and the Knights of Labor. Westport, CT: Greenwood Press, 2000. Atwood, Henry Clinton. The Master Workman: Or, True Masonic Guide: Containing Elucidations of the Fundamental Principles of Free-Masonry, Operative and Speculative - Morally and Beneficially: With Embellishments and Explanations of All the Degrees of the Blue, Or Symbolic Lodge, Chapter, Council, Encampment, Consistory, and Supreme Grand Council, Designed and Properly Arranged Agreeably to the Mode of Work and Lecturing. Also, a Complete Classification of the Various Rites to Wit: the Egyptian, Scottish, French, Ancient and Modern York. New York: Simons \& Macoy, 1850. Falzone, Vincent J. Terence V. Powderly: Middle Class Reformer. Washington, DC: University Press of America, 1978. Powderly, Terence Vincent. Thirty Years of Labor, 1859-1889. New York: A. M. Kelley, 1967.

148 Wheeler, Hoyt N. The Future of the American Labor Movement. Cambridge, New York: Cambridge University Press, 2002, S. 91.

149 Fink, Workingmen's Democracy, S. 9. Gerteis, Joseph. Class and the Color Line: Interracial Class Coalition in the Knights of Labor and the Populist Movement. Durham, NC: Duke University Press, 2007. Hild, Matthew. Greenbackers, Knights of Labor, and Populists: Farmer-Labor Insurgency in the Late-Nineteenth-Century South. Athens, GA: University of Georgia Press, 2007. Voss, Kim. The Making of American Exceptionalism: The Knights of Labor and Class Formation in the Nineteenth Century. Ithaca, NY: Cornell University Press, 1993.Weir, Robert E. Beyond Labor's Veil: The Culture of the Knights of Labor. University Park, PA: Pennsylvania State University Press, 1996. 150 Burke, Martin J. The Conundrum of Class: Public Discourse on the Social Order in America. Chicago, IL: University of Chicago Press, 1995, S. 243, FN 7.

151 Fink, Workingmen's Democracy, S. 6 f. 
weise versuchten die KoL Streiks zu verhindern. Powderly sah in den Streiks ein Relikt der Barbarei. ${ }^{152}$ Er befürwortete Schlichtungsentscheidungen und die Waffe seiner Wahl sollte der Boykott sein. Da er aber nicht alle locals der KoL kontrollieren konnte, kam es doch immer wieder zu Streiks unter Beteiligung der Knights, darunter zwei erfolgreiche Streiks gegen die Eisenbahnlinien unter der Kontrolle Jay Goulds im Jahre 1885. ${ }^{153}$ Trotz der Zurückhaltung in der Zentrale der KoL entwickelte sich die Organisation schnell zu einer militanten Gewerkschaft, die aus allen Teilen der Gesellschaft Zulauf bekam.

Die Knights of Labor hatten aber durchaus Konkurrenz. Andere Gewerkschaften widersetzten sich den breiten Reformzielen der KoL und setzten sich für pragmatische Verbesserungen am Arbeitsplatz ein. Samuel Gompers, ein in London geborener Zigarrenmacher aus einer jüdisch-niederländischen Familie, unterstützte, was er „pure and simple unionism“ nannte. ${ }^{154}$ Gompers gründete 1881 die Federation of Organized Trades and Labor Unions in 1881 und reorganisierte diesen Verband 1886 als American Federation of Labor (AFL), einer Dachorganisation der Gewerkschaften in den Vereinigten Staaten. Sein Plan klang einfach: Organisiere die Facharbeiterschaft, weil die die höchste Durchsetzungsfähigkeit hat, und setze dich in Streiks für die Verbesserung der Arbeitsbedingungen und höhere Löhne in einzelnen Unternehmen ein. Dabei sollten die Einzelgewerkschaften autonom bleiben, d.h., sie entscheiden u.a. darüber, wer ihnen als Mitglied beitreten durfte. Dies führte in der Praxis zu einem Ausschluss von Frauen und African Americans aus vielen Einzelgewerkschaften. Gompers „Brot-und-Butter-Gewerkschaft“ interessierte zunächst wenige arbeitende Menschen. 1886 hatte die AFL 138.000 Mitglieder - im Vergleich dazu hatten die KoL 730.000. Doch sorgte die weitere historische Entwicklung für den raschen Niedergang der Knights und den überraschenden Aufstieg der AFL. ${ }^{155}$

152 Lens, Sidney. The Crisis of American Labor. New York: Sagamore Press, 1959, S. 64.

153 Reef, Working in America, S. 150. Brenner, Aaron, Day, Benjamin und Ness, Immanuel. The Encyclopedia of Strikes in American History. Armonk, NY: M.E. Sharpe, 2009, S. XVIII.

154 Julie Greene kann zeigen, dass die American Federation of Labor weitaus politischer war, als Gompers dies darstellte. Greene, Julie. Pure and Simple Politics: The American Federation of Labor and Political Activism, 1881-1917. Cambridge, New York: Cambridge University Press, 1998, S. 3, 60 .

155 Gompers, Samuel. Attitude of Labor towards Government Regulation of Industry. Annals of the American Academy of Political and Social Science 32 (1908):75-81. Ders. Free Speech and the Injunction Order. Annals of the American Academy of Political and Social Science 36, no. 2 (1910):1-10. Ders. The Labor Movement and Peace. The Advocate of Peace (1894-1920) 67, no. 1 (1905):12-13. Ders. The Limitations of Conciliation and Arbitration. Annals of the American Academy of Political and Social Science 20 (1902):29-34. Ders. Organized Labor in the Campaign. The North American Review 155, no. 428 (1892):91-96. Ders. Organized Labor's Attitude Toward 
Während die KoL und der AFL sich gegenseitig die Mitglieder abspenstig machten - wobei die AFL am Ende siegen sollte - arbeiteten radikale Sozialisten und Anarchisten am Rande des linken politischen Spektrums an weitergehenden Zielen. Die Radikalen bestanden zum überwiegenden Teil aus europäischen Zuwanderungsländern, in denen der europäische Sozialismus mit seiner Betonung der revolutionären Methode prononciert vertreten war. ${ }^{156}$ Die Anarchisten hatten Ähnliches im Sinn, wollten aber in der revolutionären Situation auch noch gleich den Staat abschaffen. ${ }^{157}$ Beide Gruppen, die sich dem Vorwurf ausgesetzt sahen, sie zögen revolutionäre Rhetorik praktischen Verbesserungen vor, unterstützten die sehr populäre und auch von der AFL geforderte Einführung des Achtstundentags. ${ }^{158}$

Seit den 1840er Jahren hatte die Arbeiterschaft versucht, den allgemein üblichen Zwölfstundentag abzuschaffen. Für den Schlosser und Begründer der Grand Eight Hour League of Massachusetts, Ira Steward (1831-1883), bedeutete der verkürzte Arbeitstag nicht nur die Verfügung über mehr Freizeit, sondern auch die Möglichkeit zur Bildung und damit der Ausweg „,...] from slavery and ignorance. "159 Um die Mitte der 1880er Jahre wurde deutlich, dass die Schere zwischen Gewinnen und Löhnen immer größer wurde. Der Achtstundentag anstelle des inzwischen üblichen Zehnstundentags hätte in diesem Zusammenhang auch eine indirekte Lohnerhöhung mit sich bringen können. ${ }^{160}$ Die radikalen Sozialisten und Anarchisten setzten sich mit Vehemenz für die Reduktion der Arbeitszeit bei vollem Lohnausgleich ein. Man einigte sich darauf, am 1. Mai 1886 einen nationalen Generalstreik auszurufen, um den Achtstundentag durchzu-

Child Labor. In. Annals of the American Academy of Political and Social Science 27 (1906):79-83. Ders. The Peace Crusade in Boston. Organized Labor's Contribution to International Peace. The Advocate of Peace (1894-1920) 61, no. 5 (1899):110 - 112. Miles, Nelson A., Hampton, Wade, Robinson, Harry P. und Gompers, Samuel. The Lesson of the Recent Strikes. The North American Review 159, no. 453 (1894):180 - 206.

156 Addams, Jane. Twenty Years at Hull-House: With Autobiographical Notes. New York, Toronto: Signet Classic, 1960, S. 135.

157 Eltzbacher, Paul. Anarchism. New York, London: Benj. R. Tucker. A.C. Fifield, 1908, S. 31-36, 72-80, 100 -106, 121-127, 149-159, 276 - 280. Addams, Twenty Years at Hull-House, S. 135.

158 Haverty-Stacke, Donna T. America's Forgotten Holiday: May Day and Nationalism, 18671960. New York: New York University Press, 2009, S. 11-24.

159 Bauer, Stephan und Maylander, Alfred. The Road to the Eight-Hour Day. In. Monthly Labor Review. 1919 Aug 1; 9 (2):41-65.

160 Roediger, David R. und Foner, Philip Sheldon. Our Own Time: A History of American Labor and the Working Day. London, New York: Verso, 1989, S. 123-144. 
setzen. ${ }^{161} 350.000$ Arbeiter (und wenige Arbeiterinnen) beteiligten sich an diesem Streik, der in der Forschung als „the Great Upheaval“ behandelt wird. ${ }^{162}$ In der Folge kam es zu mehr als 1.400 einzelnen Streiks, so dass sich sogar Friedrich Engels beeindruckt zeigte. ${ }^{163}$

Alle Fraktionen der Arbeiterbewegung kamen am 1. Mai 1886 in Chicago zusammen, um die bisher größte Kundgebung für die Einführung des Achtstundentags zu veranstalten. Auch die Knights of Labor nahmen an dieser Demonstration teil, obwohl Powderly und die Führungsgruppe um ihn herum sich an Veranstaltungen für die Verkürzung der Arbeitszeit nicht einsetzen wollten, weil sie eine Radikalisierung der Bewegung befürchteten. Eine Gruppe von Anarchisten unter Führung von Albert Richard Parsons (1848-1887) und August Vincent Theodor Spies (1855-1887), ein in Hessen geborener Immigrant, gelernter Polsterer und Journalist, führten die Achtstundenbewegung in Chicago an. Ihre revolutionäre Rhetorik versetzte die besitzenden Klassen in Panik. ${ }^{164}$ Unterstützt wurden sie von dem kürzlich aus Deutschland eingereisten Johann Most (1846-1906), einem ehemaligen sozialdemokratischen Reichstagsabgeordneten, der sich von der Sozialdemokratie losgelöst hatte und nun zum Anarchismus tendierte. Samuel Gompers war ebenfalls anwesend, um die Gewerkschaften in Chicago zu mobilisieren, obwohl er sich privat reserviert zeigte. ${ }^{165}$ Seine Facharbeiter waren Teil der Arbeiterelite und etliche von ihnen arbeiteten noch in kleinen Betrieben oder Werkstätten, in denen die Beziehungen von Arbeitern zur Betriebsleitung durch persönliche Bekanntschaft geprägt waren. In ihren schwarzen Anzügen und gestärkten Hemden standen sie im scharfen Kontrast zur Masse der Streikenden in McCormicks riesiger Landmaschinenfabrik. Es kam zu Auseinandersetzungen mit Streikbrechern vor den Toren der McCormick-Werke und Polizei und Pinkerton-Detektive beschützten die Streikbrecher. 1885 hatte McCormick eine Lohnsenkung zurücknehmen müssen, weil seine Arbeiter gestreikt hatten und die Geschäftsleitung unter Führung von Cyrus Hall McCormick Jr. (1859-1936) war entschlossen, die Macht der Gewerkschaften im folgenden

161 Im Untersuchungsbericht des Senats zum Verhältnis von Kapital und Arbeit aus dem Jahr 1883 wiesen die Zeugen immer wieder auf die Notwendigkeit des Achtstundentags hin. United States; Congress; Senate; Committee on Education and Labor. Report of the Committee of the Senate upon the Relations between Labor and Capital, Band 1, S. 295-301, 328-333, 459, 461. 162 Green, James R. Death in the Haymarket: A Story of Chicago, the First Labor Movement, and the Bombing that Divided Gilded Age America. New York: Pantheon Books, 2006, S. $145 \mathrm{f}$.

163 Sylvers, Malcolm. Marx, Engels und die USA - ein Forschungsprojekt über ein wenig beachtetes Thema. Internationale Marx-Engels-Stiftung. Marx-Engels-Jahrbuch 2004. Berlin: Akademie Verlag, 2005, S. 31-53, S. $47 \mathrm{f}$.

164 Horowitz, Irving Louis. The Anarchists. New Brunswick, NJ: Aldine Transaction, 2005, S. 423. 165 Avrich, The Haymarket Tragedy, S. 94. 
Jahr zu brechen. Sie kaufte neue Maschinen, verhängte eine Aussperrung und setzte neue, ungelernte Arbeitskräfte ein, um die Gewerkschaftsmitglieder aus dem Betrieb zu drängen. ${ }^{166}$

Am 1. Mai 1886 demonstrierten 45.000 Arbeiter friedlich auf der Michigan Avenue, um ihre Unterstützung für den Achtstundentag zu bekunden. Viele stimmten ein Lied an, das die Ideen der Bewegung zum Ausdruck brachte.

We mean to make things over; we're tired of toil for naught

But bare enough to live on: never an hour for thought.

We want to feel the sunshine; we want to smell the flowers;

We're sure that God has willed it, and we mean to have eight hours.

We're summoning our forces from shipyard, shop, and mill:

Eight hours for work, eight hours for rest, eight hours for what we will!167

Die Situation geriet außer Kontrolle, als am 3. Mai Streikende vor den Toren von McCormick die herangebrachten Streikbrecher angriffen und die Polizei auf die Arbeiter das Feuer eröffnete. Es gab mindestens zwei Tote und zahlreiche Verletzte. Die Radikalen forderten die Arbeiter auf, sich zu bewaffnen und sich zahlreich auf dem Haymarket Square zu versammeln. ${ }^{168}$

Die Demonstration am Abend des 4. Mai war schlecht besucht. Nicht mehr als 3.000 Arbeiter hatten sich im Nieselregen versammelt, um Spies, Parsons und andere Redner zu hören. Der Bürgermeister Carter Henry Harrison, Sr. (18251893), ein arbeiterfreundlicher demokratischer Politiker, besuchte die Demonstration und befand, die Versammlung sei friedlich. Wenig später ließ Captain John „Blackjack“ Bonfield (1836-1898) von der Chicagoer Polizei, ein Mann der den Ruf genoss, hart gegen Arbeiter durchzugreifen, seine Männer gegen die Demonstranten vorgehen, die inzwischen auf eine Gruppe von 800 bis 1.000 Menschen zusammengeschmolzen waren. ${ }^{169}$

Plötzlich warf jemand eine Bombe zwischen die Polizeibeamten. Die Polizeikräfte begannen, auf die Demonstranten (und die eigenen Leute) zu schießen. Es ergab sich eine allgemeine Melée, alles war sehr unübersichtlich. Verwundete und Tote lagen auf der Straße. Sieben Polizisten und eine unbekannte Anzahl von

166 Avrich, The Haymarket Tragedy, S. 188. Green, Death in the Haymarket, S. 148.

167 Das Lied „Eight Hours“ war 1878 von Rev. Jesse Henry Jones komponiert worden. Der Text stammte von I. G. Blanchard. Shrock, Joel. The Gilded Age. Westport, CT: Greenwood Press, 2004, S. $188-189$.

168 Avrich, The Haymarket Tragedy, S. 189f. Green, Death in the Haymarket, S. $170 \mathrm{f}$.

169 Avrich, The Haymarket Tragedy, S. 97 f. Green, Death in the Haymarket, S. 121-126. 
Zivilisten wurden getötet. 67 Polizisten und etwa 30 Streikende wurden zum Teil schwer verletzt. ${ }^{170}$

Die Neuigkeiten vom „Haymarket Riot“ erschütterten die Nation. Die Schuldigen schienen leicht auszumachen zu sein. Anarchisten, Radikale, Gewerkschaftsmitglieder, Streikende und Einwanderer wurden kollektiv zu Sündenböcken gemacht. Die nationale Hysterie war am deutlichsten In Chicago zu spüren. Die Polizei verhaftete Spies und andere Redner der Versammlung am Haymarket Square. Hunderte Radikale wurden ins Gefängnis geworfen. Keinem der Verhafteten konnte nachgewiesen werden, die Bombe geworfen $\mathrm{zu}$ haben. Acht von ihnen, mehrheitlich deutsche Einwanderer mit anarchistischen Überzeugungen, wurden wegen Mordes angeklagt und verurteilt. ${ }^{171}$

Der Justizminister des Staates Illinois Julius S. Grinnell (1842-1898), forderte „[... to] make examples of them, hang them, and you save our institutions. " 172 Die Angeklagten wurden verurteilt, nicht, weil sie eine Bombe geworfen hatten, sondern weil sie ihre Ideen öffentlich propagiert hatten. Sie alle gehörten zum Umfeld der Arbeiter-Zeitung, eines anarchistischen Blattes aus Chicago. ${ }^{173}$ Vier wurden gehängt, einer zog es vor, sich in der Zelle selbst zu töten, drei erhielten Gefängnisstrafen. ${ }^{174}$ Unter dem Galgen sprach August Spies prophetische Worte: „The time will come when our silence will be more powerful than the voices you throttle today. “175

Am 26. Juni 1893 begnadigte der Gouverneur des Staates Illinois John Peter Altgeld nach eingehender Beratung auch durch den deutschen Arbeiterführer George Schilling die drei noch lebenden Gefangenen. ${ }^{176}$ Er verurteilte das Gerichtsverfahren als einen Schauprozess und schloss „Captain Bonfield is the man

170 Avrich, The Haymarket Tragedy, S. XI. Green, Death in the Haymarket, S. 5.

171 Green, Death in the Haymarket, S. 121-126.

172 Horowitz, The Anarchists, S. 433.

173 Margulies, Phillip und Rosaler, Maxine. The Devil on Trial: Witches, Anarchists, Atheists, Communists, and Terrorists in America's Courtrooms. Boston, MA: Houghton Mifflin Co, 2008, S. $29-69$.

174 Albert Parsons, August Spies, George Engel (1836-1887) und Adolph Fischer (1858-1887) wurden erhängt. Louis Lingg (1864-1887) tötete sich in seiner Zelle mit einer Stange Dynamit. Oscar Neebe (1850 - 1916) wurde zu 15 Jahren Gefängnis verurteilt. Die Todesurteile gegen Michael Schwab (1853-1898) und Samuel Fielden (1847-1922) wurden von Gouverneur Richard James Oglesby in lebenslange Haft umgewandelt.

175 Green, Death in the Haymarket, S. 270.

176 Altgeld, John Peter. Reasons for Pardoning Fielden, Neebe and Schwab. Chicago: n.p., 1893. Keil, Hartmut und Jentz, John B. German Workers in Chicago: A Documentary History of WorkingClass Culture from 1850 to World War I. Urbana, IL: University of Illinois Press, 1988, S. 104. 
really responsible for the death of the police officers." ${ }^{\text {"177 }}$ Diese juristisch und politisch einwandfreie Entscheidung kostete Altgeld die Karriere. Trotz der allgemeinen Entrüstung über Altgelds Entscheidung zögerte er keinen Moment. „If I decide they are innocent, I will pardon them, if I never hold office another day. “178 Er wurde in der Folge als „Kommunist“ und „Gehilfe von Mördern“ vor allem von Theodore Roosevelt denunziert. ${ }^{179}$

Die Haymarketbombe zeitigte langfristige Veränderungen. Für mehrere Jahrzehnte symbolisierte sie ein tiefsitzendes Misstrauen der amerikanischen Bevölkerung gegen die organisierte Arbeiterschaft. Gewerkschaften und politische Parteien links von den Demokraten wurden mit Gewalt, Terror und ausländischen Berufsrevolutionären gleichgesetzt. Der Journalist John Swinton (18291901) bezeichnete die Bombe als „,...] a godsend to all enemies of the labor movement. "180 Ihr fiel auch die Bewegung zur Einführung des Achtstundentags zum Opfer und die beendete den Aufstieg der Knights of Labor. Sie verloren den Great Southwestern Railroad Strike im Frühjahr 1886 gegen Jay Gould und erholten sich von diesem Rückschlag nie wieder. ${ }^{181}$ Damit bot sich der American Federation of Labor eine historische Chance. Die vom Ausgang der Arbeitskämpfe enttäuschten Facharbeiter wendeten sich von den radikalen Kräften ab und organisierten sich rasch in der AFL. Unter Samuel Gompers stieg sie rasch zur wichtigsten Gewerkschaftsorganisation auf, die erst in den 1930er Jahren und unter den Bedingungen der Weltwirtschaftskrise durch den industriegewerkschaftlich organisierten Congress of Industrial Organizations (CIO) Konkurrenz bekam. Bis zu seinem Tod im Jahre 1924 arbeitete Gompers daran, die AFL zu einem disziplinierten Gewerkschaftsdachverband $\mathrm{zu}$ formen, der von der Unternehmerseite ernst genommen wurde. In Abkehr von den radikalen Forderungen der Gewerkschaften vor der Haymarket Riot vertrat die AFL gemäßigte und pragmatische Forderungen und erzielte praktische, aber begrenzte Erfolge. Höhere Löhne, kürzere Arbeitszeiten, die unter sparsamer Verwendung von Streiks und Boykotts erzielt werden konnten, schonten auch die Gewerkschaftskasse und erlaubten es,

177 Smith, Urban Disorder and the Shape of Belief, S. 171.

178 Browne, Waldo R. Altgeld of Illinois: A Record of His Life and Work. New York: B. W. Huebsch, 1924, S. 24.

179 Ferguson, Robert A. The Trial in American Life. Chicago: University of Chicago Press, 2007, S. 230. Altgeld, John Peter. Reply to Roosevelt. Being a Speech of Ex-Governor John Peter Altgeld, Delivered before the Ohio Association of Democratic Clubs of Toledo, August 1, 1900. [Toledo, OH: Eigenverlag?; 1900], S. $10-15$.

180 Avrich, The Haymarket Tragedy, S. 429.

181 Case, Theresa Ann. The Great Southwest Railroad Strike and Free Labor. College Station, TX: Texas A\&M University Press, 2010. 
ein gewerkschaftseigenes Sozialprogramm aufzulegen. Dieser Pragmatismus und die erzielten Erfolge ließen die Mitgliederzahlen der AFL rapide ansteigen. 1898 hatte die Gewerkschaft ca. 250.000 Mitglieder, 1904 waren es über 1.500.000. ${ }^{182}$

Gompers vertraute nicht auf die Hilfe der Regierung. Er wies darauf hin, dass die Gerichte, der Gesetzgeber und die Exekutive auf Seiten der Unternehmer standen. Unter den politischen und ökonomischen Bedingungen der Zeit macht der Brot-und-Butter-Pragmatismus der AFL durchaus Sinn. Die Arbeiteraristokratie - die Facharbeiterschaft - konnte so ihre wirtschaftliche und politische Position verbessern. Der allergrößte Teil der rasch wachsenden ungelernten Arbeiter jedoch hatte wenig von Gompers Pure and Simple-Gewerkschaftspolitik. Die frontalen Angriffe der Regierung und der Unternehmer auf die frühe Gewerkschaftsbewegung im Nachgang des „Schicksalsjahrs“ 1886 resultierten also in einem gewerkschaftlichen Pragmatismus, der auf die Minderheit der Facharbeiter als den Kern der Gewerkschaftsbewegung ausgerichtet war. Der Anteil dieser Facharbeiter nahm allerdings nach 1870 langsam ab. ${ }^{183}$ Hinzu kam, dass die ethnische Komposition der Arbeiterschaft sich nach 1880 radikal veränderte. Vor 1880 war die Labor Force ethnisch relativ homogen gewesen: Es dominierten Arbeiter aus nordeuropäischen Ländern, von denen ein großer Prozentsatz Facharbeiter waren. Mit der „neuen Immigration“ kamen jedoch Menschen aus Süd- und Osteuropa, aus China und mit der Great Migration nach 1890 auch African Americans auf der Suche nach Arbeit in die Industriestädte. Sie waren angelernte bzw. Hilfsarbeiter. Die Konzentration des AFL auf Facharbeiter des alten Typs führte zu einer großen Benachteiligung der ungelernten und Hilfsarbeiter in der Lohnentwicklung nach $1880 .{ }^{184}$ Das hatte den positiven Verstärkereffekt, dass gelernte Arbeiter ihre Löhne und ihre Arbeitsbedingungen auf Kosten der ungelernten verbessern konnten. Dies stellte die Raison d'Être für die AFL dar, führte jedoch zur Spaltung der Arbeiterklasse in ethnische Gruppen, den weit gehenden Ausschluss der ungelernten Arbeiter und Arbeiterinnen aus der AFL. Das Prinzip der lokalen Gewerkschaftsorganisation anstelle der Industriegewerkschaften und der auf eine Verbesserung des Lebensstandards abzielende Pragmatismus der AFL erschwerten die Organisation einer Gewerkschaft, die alle Arbeiter, gleichgültig ob Männer oder Frauen, Weiße oder African Americans, im Land geborene

182 Robertson, David Brian. Capital, Labor, and State: The Battle for American Labor Markets from the Civil War to the New Deal. Lanham, MD: Rowman \& Littlefield Publishers, 2000, S. 69. 183 1870: 20.5 Prozent; 1880: 17.6 Prozent; 1890: 19 Prozent; 1900: 17 Prozent. Dawson, Andrew. The Paradox of Dynamic Technological Change and the Labor Aristocracy in the United States, 1880 - 1914. Labor History. 1979; (20):325-351, S. 330 f.

184 Greene, Julie. Pure and Simple Politics: The American Federation of Labor and Political Activism, 1881-1917. Cambridge, New York: Cambridge University Press, 1998, S. 21-23. 
oder zugewanderte, zusammengeschlossen hätte. Stattdessen blieben die Radikalen unter sich, weitgehend zur Wirkungslosigkeit verdammt, während die AFL vor lauter Pragmatismus und Dünkel der Arbeiteraristokratie zu einem Verband wurde, der auch vor offen sexistischen und rassistischen Positionen nicht zurückschreckte. ${ }^{185}$

Vier Elemente eines Dispositivs kommen hier zusammen: alltägliche Praktiken des Ausschlusses, Diskurse der Minderwertigkeit und der Unangepasstheit, Institutionen, die diese Diskurse in Entscheidungen umsetzen (Nichtaufnahme von Hilfsarbeitern, Minderheiten und Frauen) und Gesetze, wie der Chinese Exclusion Act, die auf allen diesen Faktoren aufbauen und sie in einem Feed-BackLoop verstärken. Hier liegt ein weiterer Lock-in-Effekt, der die Arbeiter- und Gewerkschaftsbewegung auf eine expansionistische und chauvinistische Generallinie vorbereitete, die in den Jahren nach 1893 an Akzeptanz gewinnen sollte. Auf der anderen Seite stand die Unfähigkeit oder der mangelnde Wille des politisch bewusstesten Teils der sozialistischen Bewegung, über ihre ethnischen Wurzeln hinauszugehen und Menschen $\mathrm{zu}$ organisieren, die Englisch als erste Sprache gelernt hatten. Die sektiererische Socialist Labor Party (SLP), 1876 gegründet, 1877 in SLP umbenannt, umfasste mehrheitlich deutsch-jüdische Einwanderer, darunter fast keine weiblichen Mitglieder, und war kulturell und sprachlich vom Rest der Arbeiterschaft vollkommen isoliert. Die SLP war auf New York konzentriert und versuchte dort, bei Wahlen ihre Kandidaten durchzubringen. In der Gewerkschaftsarbeit war die Partei nicht sonderlich erfolgreich, weil sie auf ihre eigene sozialistische Gewerkschaft, die Socialist Trade and Labor Alliance (gegr. 1895) setzte, während sie die AFL links liegen ließ. ${ }^{186}$ Die AFL blieb demzufolge bis

185 Greene, Julie. Pure and Simple Politics, S. 40 f. Stromquist, Shelton. United States of America. Linden, Marcel van der und Rojahn, Jürgen (Hg.). The Formation of Labour Movements, 1870 1914: An International Perspective. Leiden, New York: E.J. Brill, 1990, 2 Bände, Band 2: S. 543 - 578, S. 569. Zur Position von Frauen in der AFL siehe Nutter, Kathleen Banks. The Necessity of Organization: Mary Kenney O’Sullivan and Trade Unionism for Women, 1892-1912. New York: Garland Pub, 2000, S. XV-XXIV, 1-27.

186 Socialist Labor Party. Proceedings of the National Convention of the Socialist Labor Party Held at Turner Hall, Allegheny City, PA, Commencing Dec. 26th, 1879. Detroit, MI: National Executive Committee of the Socialist Labor Party, 1880, S. 5-17. Der Text führt u. a. die fast ausnahmslos deutschsprachigen Zeitungen der Partei an. 1889 kam es zu einem ernsthaften Zerwürfnis zwischen den deutschen und den amerikanischen Parteimitgliedern der SLP in New York. Socialist Labor Party. Proceedings of the National Convention Held in Chicago, September 28, 1889. Cincinnati, OH: J. Willig, 1889, ohne Paginierung. De Leon, Daniel und Harriman, Job. The Socialist Trade and Labor Alliance versus the „Pure and Simple“ Trade Union: A Debate Held at the Grand Opera House, New Haven, Conn., November 25, 1900, between Daniel De Leon Representing the Socialist Trade \& Labor Alliance and the Socialist Labor Party, and Job Harriman Representing the „Pure and Simple“ Trade Union and the Social Democratic Party. New York: New 
1938 eine reine „Brot-und-Butter-Gewerkschaft“, die ihrerseits nicht offen war für Immigranten und angelernte Kräfte. Diese Verzettelung der Kräfte sowie der Chauvinismus und Rassismus der AFL bewirkten einen weiteren Lock-in, als dessen Konsequenz Gompers und die AFL die territoriale Expansion der USA und ihre Auswirkungen akzeptierten. Sie wendeten sich jedoch energisch gegen jede Form der Annexion, weil sie den Zustrom chinesischer und anderer Arbeiter in die USA befürchteten. ${ }^{187}$ Damit bereiteten sie auch jene Form des Empire vor, in der die Vereinigten Staaten keine formellen Kolonien erwarben, aber dennoch die Hegemonie über nicht auf dem nordamerikanischen Kontinentalsockel liegenden Territorien ausüben konnten. ${ }^{188}$

Die Ängste vor destruktiven sozialen Konflikten oder gar Revolten, in die die Arbeiterschaft in den 1870ern und 1880ern verwickelt sein könnten, führten zu einer Suche nach möglichen Reformen. Liberale, die zwar Sympathien für die Arbeiter hatten, sich aber gewaltsamen Lösungsansätzen widersetzten, suchten nach Formeln, die das Los der arbeitenden Menschen erleichtern könnten, doch Klassenkampf und Blutvergießen vermeiden sollten. Zwei Journalisten, Henry George (1839-1897) und Edward Bellamy (1850 - 1898), schlugen zwei Wege vor, wie dieses Ziel zu erreichen sein sollte. Beide Ansätze waren utopisch, was die Zeitgenossen aber nicht daran hinderte, beide Pläne mit sehr viel Aufmerksamkeit zur Kenntnis zu nehmen.

Der große Eisenbahnstreik von 1877 inspirierte den Journalisten Henry George aus San Francisco dazu, ein Buch zu schreiben, das sich bald zu einem Klassiker der politischen Ökonomie der USA entwickeln sollte. George kannte Armut aus seiner eigenen Biographie und hatte große Sympathien für Leute „von unten“. Er veröffentlichte 1879 „Progress and Poverty“ und widmete sein Buch „[t]o those who, seeing the vice and misery that spring from the unequal distribution of

York Labor News Company, 1900. Kipnis, Ira. The American Socialist Movement, 1897-1912. New York: Monthly Review Press, 1972, S. 19-22.

187 Davis, Horace B. American Labor and Imperialism prior to World War I. Science \& Society. 1963 Jan 1; 27 (1):70 - 76.

188 Scipes, Kim. AFL-CIO's Secret War against Developing Country Workers: Solidarity or Sabotage? Lanham, MD: Lexington Books, 2010, S. 2. Kipnis, The American Socialist Movement, S. 297. Collomp, Cathérine. L’American Federation of Labor et la politique extèrieures des ÉtatsUnis: De l'antiimpèrialism á la coopération idéologique. Ricard, Serge und Bolner, James. La République impérialiste: L'expansionnisme et la politique extérieure des Etats-Unis, 1885-1909. Études et Documents. Aix-en-Provence: Université de Provence, 1987, S. 181-193. Man sollte der Fairness halber bemerken, dass auch die Mehrzahl der amerikanischen Sozialisten den Krieg mit Spanien 1898 befürwortete. Quint, Howard H. American Socialists and the Spanish-American War. American Quarterly. 1958 Jul 1; 10 (2):131-141. 
wealth and privilege, feel the possibility of a higher social state and would strive for its attainment." 189

In seiner Untersuchung erörterte ein Paradox des amerikanischen Lebens: Wie kann es in einem so reichen Land so viel Ungleichheit geben? Kalifornien war ein Paradebeispiel dafür, wie der Einfluss der Monopole anwuchs, wie das Land von großen Gesellschaften aufgekauft wurde und als Spekulationsmasse verkauft wurde. In „Progress and Poverty“ entwickelte er eine wirtschaftswissenschaftliche Theorie, die die Verknappung von Land als Ursache für die Armut der Mehrheit verantwortlich machte. Landspekulanten - so George - trugen nichts zur Wirtschaft bei und erzielten dennoch riesige Profite. ${ }^{190}$

Als Panazee für dieses Problem empfahl er eine Steuer auf brachliegendes Land. Eine prohibitive Steuer, die Single Tax, sollte die Spekulation unterbinden und damit auch Armut mit Stumpf und Stiel ausrotten. Industriearbeiter würden sich wieder auf dem nun billigen Land niederlassen. Die Löhne für Arbeiter würden durch die Verknappung der industriellen Reservearmee steigen. Die Sicherheit des Arbeitsplatzes würde zunehmen. Die Regierung würde letztlich überflüssig bzw. stark reduziert. Das Ende der Korruption wäre absehbar. Ein ganzes Kapitel seines Bestsellers widmete George der Frage, wie das Leben nach der Verabschiedung der Single Tax wohl aussehen werde. ${ }^{191}$ Um deutlich zu machen, dass es Handlungsbedarf gebe, endete sein Buch mit einem apokalyptischen Kapitel, das ausmalte, was passiere, wenn nichts unternommen werde, um die Armut zu beenden. ${ }^{192}$ Allgemeine Armut, Seuchen und Revolution seien im gegenwärtigen System unvermeidlich. ${ }^{193}$

Seine Single Tax öffne einen Ausweg aus dem Klassenkampf. In Georges Ansicht gab es keine Feindschaft zwischen ehrlichen Arbeitern und fleißigen Kapitalisten. Der wirkliche Bösewicht war der gierige Landspekulant. Dank der Single Tax könne man dieser Gruppe nun den Garaus machen. Georges Botschaft fand offene Ohren. Der Text erlebte eine millionenfache Verbreitung. Ganze Generationen von Reformern im In- und Ausland bezogen sich auf Henry George.

189 George, Henry. Progress and Poverty: An Inquiry into the Cause of Industrial Depressions, and of Increase of Want with Increase of Wealth. The Remedy. San Francisco, CA: W. M. Hinton \& Co., printers, 1879, S. V. Die verschiedenen Ausgaben des Textes unterscheiden sich sehr. Die Originalausgabe war mir nicht zugänglich. Ich zitiere hier die Ausgabe von 2005. George, Henry. Progress and Poverty. New York: Cosimo Inc., 2005.

190 George, Henry. Progress and Poverty, S. 233 f.

191 George, Henry. Progress and Poverty, S. 321-334.

192 George, Henry. Progress and Poverty, S. 376.

193 George, Henry. Progress and Poverty, S. 380. 
Das späte 19. Jahrhundert erlebte zahlreiche Visionen eines besseren Lebens. Amerikaner und Amerikanerinnen zerbrachen sich die Köpfe darüber, wie man Verstädterung, Industriekapitalismus und Klassengegensätze miteinander vereinbaren könne. Henry George versuchte seine Ideen als Kandidat der Arbeiter für das Amt des New Yorker Bürgermeisters umzusetzen. Bellamys Nationalismus hatte größere Unterstützer unter den gebildeten Mittelschichten. Wie weit die soziale Utopie sogar in die Kreise der hohen Politik reichte, ersieht man an der arglosen Bemerkung Präsident Hayes angesichts des Eisenbahnstreiks von 1877: „Can't something [be] done by education of the strikers, by judicious control of the capitalists, by wise general policy to end or diminish the evil?“. ${ }^{194}$ Selbst der amerikanische Präsident erhoffte eine Reform, die auf der Erziehung und Überwachung aller am Streik beteiligten Gruppen gründen sollte. Die Arbeiterschaft sah ihr Ziel weniger in einer Kontrolle der Kapitalisten als in der Wahrnehmung ihrer Interessen: kürzere Arbeitszeiten, höhere Löhne und Wiedergewinnung der verlorenen Autonomie am Arbeitsplatz. 1879 blickte ein Lederfärber aus Massachusetts auf sein Leben zurück und bewertet die Auswirkungen der Industrialisierung folgendermaßen: „What do the Mechanics of Massachusetts say to each other? I will tell you: ,We must have a change. Any thing is better than this. We cannot be worse off, no matter what the change is“ "“195

Steigende Frustration und zunehmende Unzufriedenheit würden in den nächsten Jahren eine Situation herbeiführen, die Bauern und Arbeiter ihre Differenzen überwinden ließ und den Boden bereitete für die Gründung einer neuen politischen Partei, der Populisten oder People's Party.

194 Williams, Diary and Letters of Rutherford Birchard Hayes, Band 3, S. 440. Miller, Stephen. Special Interest Groups in American Politics. New Brunswick, NJ: Transaction Books, 1983, S. 91. 195 Smith, Craig R. Silencing the Opposition: Government Strategies of Suppression. Albany, NY: State University of New York Press, 1996, S. 125. 